\title{
The Main Text
}

\section{(i) Friends in Council}

Five years ago this day Dr Laycock, Professor of the Practice of Medicine in the University of Edinburgh, left York for Edinburgh to take steps for offering himself to the electors, to fill the vacant chair which Professor William Pulteney Alison \{b\} had resigned. On Monday, 13 August Dr James Y. Simpson \{b\}, Professor of Midwifery in the University ${ }^{1}$ wrote to Dr Laycock as follows:

My Dear Dr Laycock.

Dr Alison is to resign to-day or tomorrow the chair of the Practice of Physic, his health being now very bad indeed. I do not know how it will be disposed of, or who will be considered for it. But perhaps it would be a professorship for which you would consider it right to come forward. It is certainly the highest medical chair in our Scotch Universities, and consequently I may say in Great Britain. Think over it or rather act at once, if you have any idea of it. None of us professors can or will interfere in any way. The whole patronage is in the hands of the Town Council who always strive to put the right man in the right place. At all events excuse me troubling you with this note on the matter. Kindest regards to Mrs Laycock and Miss Laycock. Yours very truly, J. Y. Simpson. ${ }^{2}$

This letter was received on Tuesday morning. The Provincial Medical and Surgical Association was to commence its meeting on Wednesday at York, and Dr Laycock had to receive several members of the body at dinner-Dr Semple, Dr Lanchester, W. B. Richardson, Purcell[?]-and could not leave York. He therefore wrote to ask for further information and especially to know whether a graduate of the University of Göttingen and extra-urbem Licentiate of the Royal College of Physicians of London was eligible. Miss Laycock, he intimated, was a master. He thus secured time for reflection.

Dr Laycock's thoughts were of the most varied character. It had never entered into any scheme of his to seek the honor thus brought before him. Dr Simpson had not over-stated its importance and position in the medical profession. To fill the chair of Gregory and Cullen might well be an object of the highest ambition; and Dr Laycock was ambitious. But he was not ambitious of cash so much as desirous of power over the minds of men. This he had exercised largely through the press, although to a great extent secretly, for none except himself knew to what extent he contributed to the public papers and journals. For several years in particular he had been an active member on the staff of the [British and Foreign] Medico-Chirurgical Review, his connexion with which began in October 1842 with a paper on general hygiene, when Sir John (then Dr) Forbes was Editor, and subsequently during the editorship of Dr Carpenter and Parkes. He had thus abundant

1 Engraving of J. Y. Simpson, from a photograph by Moffat, 1869.

${ }^{2}$ Letter, J. Y. Simpson to T. Laycock, 13 August $1855\{\mathrm{t}\}$. 


\section{Thomas Laycock}

opportunities for influencing the mind of the profession upon all the great questions of the day, whether medico-scientific, ethical, scientific or practical, and he felt a pride in exercising this influence behind the screen of periodical anonymousness. The praise was less to him than the feeling of wielding power.

To occupy the chair of Alison and Cullen would be to enjoy larger and nobler opportunities of this kind, and in particular to give him the occasion to carry out an ambitious dream he had of re-modelling the science and practice of medicine in accordance with the progress of modern science and thus take rank with a Galen, Boerhaave or Cullen. It seemed to him a position from whence he could guide and develop the minds of the rising generation of British physicians into all truth, and leave upon the profession a stamp of goodness and greatness that would not easily be effaced. Such were his dreams. But the chair would also allow him the means of escape from the miseries, petty though they were, which were inflicted upon him by the envy and hatred of professional rivals in York.

In 1841 the Provincial Medical and Surgical Association met in York, when he was made the object of an intemperate attack by Dr Hastings (see Dublin Medical Press, August 1841) acting under the influence of Dr Thomas Simpson, a physician of York, and Mr Husband, a surgeon, protégé of the latter. Dr Laycock had during the previous year (1840) published his Treatise on the [Nervous] Diseases of Women, not without exciting unpleasant feelings on the part of his contemporaries at York. These had been especially shown on the occasion of some differences of opinion as to the publication of the proceedings of the York Medical Society. Dr Laycock had sent a report of a debate to the Dublin Medical Press, unfortunately without first communicating his intention; not thinking there could be two opinions as to the utility to the Society of such publication. Although the great majority of the Society accepted Dr Laycock's explanations, Drs Simpson \& Goldie, Messrs Hey, Dodsworth, and Husband expressed their intention of resigning membership if Dr Laycock remained a member, so that rather than be a cause of a break-up of the Society Dr Laycock withdrew. In $1854 \mathrm{Mr}$ Henry Keyworth and Mr Anderson expressed their wish that Dr Laycock would rejoin the Society and after communicating with Dr Simpson and others who all expressed the pleasure it would give them to see him back. He was accordingly proposed but an attempt was made to black-ball him by three members namely Mr S. W. North, Mr George Hornby and another. The two former were old pupils of Dr Laycock and had been treated by him with every kindness and encouragement. Dr Simpson, it was observed, stayed away until the time had elapsed which according to rule is occupied with private business. The ballot was however delayed so that the vote was taken when he came in and he not only made up the proper number for voting (which he hoped to have prevented by his absence) but had also to vote for Dr Laycock. Thus disappointed of his scheme (for he was doubtless aware of the intention of North and Hornby) he resumed his old tactic of threatening to withdraw if $\mathrm{Dr}$ Laycock took his seat in the Society in pursuance of his election. This he and others (Dr Shann and Dr Williams) did privately. The despicable conduct of the old man was still baser in its nature from the fact that at the time he was thus plotting against Dr Laycock's professional place, he was enjoying Dr Laycock's hospitality and had even been dining with him en famille! $!^{3}$

\footnotetext{
${ }^{3}$ Memorandum of conversation with Dr T. Simpson, 17 November $1854\{t\}$.
} 


\section{Main Text}

Dr Thomas Simpson was the illegitimate son of a surgeon who practised in the country and who was a believer in astrology and other mysticisms. His father brought him up to his own profession, and having passed the College of Surgeons of London he settled at Knaresborough. After a while he abandoned general practice, took his degree at Edinburgh and settled at York as a physician in competition with Drs Wake and Belcome. He was a man of great fluency of speech, great plausibility and cunning and well-read in his profession. His genius was remarkably inventive as to cases which never occurred. He was an enormous boaster, and told incredible stories as to his success at chess, poetry, flute playing \&c. He was remarkably credulous; believed all the stories of mesmerism, clairvoyance and spirit rapping; subscribed to the friends of the mesmeric hospital, yet contrived to stand well with his professional brethren and retain his office of physician to the York County Hospital.

Dr Simpson's hostility to Dr Laycock had various causes. He was envious of Dr Laycock's literary fame; jealous of his rising reputation; offended because Dr Laycock had opposed the follies of mesmerism, and because he would not condescend to feed the salacious bachelor's outrageous vanity. It was certain it would never cease, and it was equally certain that those who were under obligations to him (as Husband) or expected benefits (as the younger surgeons) would seek his favour by opposition to Dr Laycock. So that, although Dr Laycock was rapidly increasing in practice, he felt that a translation to Edinburgh would be a happy as well as honourable relief from petty persecutions and their attendant vexations.

On Wednesday, 15 August 1855, the Provincial Medical and Surgical Association met and for the last time under that name. The old struggle of parties was once more renewed at York, and although the Hastings and Husband party were victorious again in a packed meeting, they were too glad to change their tactics within a few months and yield all-not even waiting for the annual meeting. The crisis Dr Laycock predicted in 1841, as inevitable, had recurred and debt and dissolution stared them in the face.

Dr Noble and Professor Williamson both of Manchester were Dr Laycock's guests at the meeting. After dinner and when the guests were gone, Dr Laycock broached the subject of Dr Simpson's letter and asked them their opinion. The following morning he was still undetermined as his wife was reluctant to leave York, and no letter had reached him from Dr Simpson. It was not without reason the wife felt reluctant to leave York. Dr Laycock had just completed the decoration of his new house which he had built expressly for a life-long residence in York. It was not a pleasant prospect to her to leave her comfortable house and sever from all her friends and connexions to begin the work[?] again. So that when the morning came, Dr Laycock found her using all possible arguments against the change or the enterprise. He called up his two friends; they promenaded in the top of his house, in consultation on the momentous question, and the decision was in favour of action. A hasty breakfast and Dr Laycock was off by the nine o' clock a.m. train to Edinburgh. Dr Lanchester was at the station, little divining Dr Laycock's errand for as yet Dr Alison's resignation was unknown.

A word regarding the two Manchester gentlemen. Dr Noble was introduced to Dr Laycock by $\mathrm{Mr}$ George Combe. Dr Noble, then plain Daniel Noble, surgeon at Manchester, was one of the sect of phrenologists and had been engaged by the Edinburgh school to write a work in defence of phrenology, for which he was to have (it was said) 


\section{Thomas Laycock}

$£ 100$ from the Henderson Trustee fund. Noble sent the proof sheets of his work to $\mathrm{Dr}$ Laycock for correction. Becoming more ambitious he graduated at St Andrews and gave a course of lectures on psychological medicine which he published and then expanded them into a work. He again sought Dr Laycock's assistance to correct the proof sheets, but Dr Laycock found him so very troublesome and the work so irksome that he was obliged to decline going on with the duty. A severe review of the work appeared in the Psychological Journal of January 1854 (Elements of Psychological Medicine) and before Dr Laycock had even seen the Journal a letter came from Noble attributing the review to Dr Laycock in the most offensive terms. Dr Laycock was utterly incapable of such conduct and motives as Dr Noble imputed to him, but in consideration of his peculiar temperament and a most ample apology he overlooked the offence. Dr Noble originally a Protestant had turned Papist from conviction and married a Roman Catholic Lady. He expressed his full belief in the verity of the story of "our Lady of La Salette" and similar impostures although an avowed metaphysician. This contradiction in his mental character always indicated to Dr Laycock a weak point either in his head or his heart, so that although on very friendly terms, he never really trusted Dr Noble in full confidence.

Professor Williamson was a wholly different character. A Wesleyan by birth and profession he had risen by his own industry to be Professor of Natural History and Physiology at Owen's College, Manchester, and to a first rank in the scientific world. He had nothing of the quack about him. Noble was for ever begging his friends to write reviews and notices of his works, with a view to a business puff. Williamson calmly bided his time. It was curious to see these two men so very unalike in friendly conversation. Upon the whole, the honest Methodist was the warmest friend as well as the most sincere. Dr Noble helped his friends that they might help him. Williamson had no back-thought.

\section{(ii) Opening the Campaign}

The line of rail from York to Berwick is not one of much interest. Immediately out of York a vast plain thickly planted, with the Howardian hills in the distance, then above Thirsk and Northallerton, the full stretch of the Vale of York between the Hambleton range to the north east and the western hills beyond Richmond, Leyburn, \&c. The Tees, as muddy as the Lyne, is next crossed and then the Weir and the Tyne, with glimpses here and there of the picturesque but nothing to arrest the eye. It is not until Berwick is approached and the outline of Holy Isle and Lindisfarne is seen that the traveller is fully roused. The scene from the bridge and viaduct is striking including the classic river of Tweed and Border town of Berwick, and as the rail way hugs the coast very closely the ocean is seen lashing the rocks and lumbering over the sands close at hand for the first few miles into Scotland. It was not a recollection of border feuds and national wars that occupied Dr Laycock's mind when he entered Scotland. The present life had too deep an interest for him. Seven years before he had entered Scotland with his wife to spend a few days at Edinburgh. On that occasion he had for the first time made Dr Simpson's personal acquaintance. Dr Simpson had repeatedly called upon Dr Laycock when passing through York, induced probably by various motives. One of these was no doubt curiosity to see the man who had published a work which has interested him and the more because his own labours had been favourably quoted by Dr Laycock. When, therefore, Dr Laycock reached 


\section{Main Text}

Edinburgh on his marriage tour he naturally called upon Dr Simpson and he was the more especially induced to do this, because it was his first visit to Edinburgh and with the exception of Mr and Mrs Chambers, knew no person there.

When the British Association [for the Advancement of Science] met in Edinburgh in the month of August 1850, Dr Laycock (together with Dr Carpenter) were entertained by Dr Simpson as his guests for a week with his usual lavish hospitality and thus a friendship begun in common professional pursuits, was cemented by common enjoyments and pleasures. Dr Simpson hastened to see Dr Laycock at the moment he left for York by the train and placed in his hand Mr Combe's work On the Divine Government, just then published with his own name inscribed as the donor.

Reminiscences of these visits mingled therefore with Dr Laycock's thoughts rather than of stories of war or of novels and it was with some anxious desire to penetrate the future that he saw the immediate environs of Edinburgh rising to his view. Was he destined to see day by day the castled rock and Arthur's Seat? Would his wife and children tread the shores of Portobello in company with those of the other citizens of Edinburgh? What possible hope of success in his enterprise could be fairly built up, when he knew at most only half a dozen persons in Edinburgh and had no reason to think any of them would assist him? Dr Simpson had expressly declared that he as a professor must remain neutral. What could Mr Chambers do? What would the one or two professional men do that $\mathrm{Dr}$ Laycock knew?

Arriving at Edinburgh Dr Laycock proceeded to the Mackay's Hotel. There he encountered a curious specimen of a character. Entering the coffee-room he found two men. One seated with a bandage over one eye, the other standing in front of the apparently sick man. Their conversation was evidently intended to attract attention. The supposed sick man received meekly the medical directions of the other (a coarse-looking sensual individual) delivered in a loud bullying, imperative tone. The sick man-indeed bothover-acted the part taken - at least to a practised professional eye like Dr Laycock's. It is not improbable, however, that the plan had succeeded with persons not experienced in professional manners and conduct.

After taking tea, Dr Laycock first directed his steps (about four to five o'clock P.M.) to Dr Simpson's, 52 Queen Street. On being shown into the library he there met Dr W. T. Gairdner $\{b\}$ one of the candidates for the vacant chair, and who turned a little pale on hearing Dr Laycock's name announced. Dr Simpson subsequently remarked (to Dr Laycock's great encouragement) that he was the most formidable competitor who had yet appeared, although it was known that Dr Bennett $\{b\}$ and Dr Wood $\{b\}$ were in the field. On enquiring Dr Laycock found that the reason why Dr Simpson had not replied to his inquiries was that he was from home. But he had telegraphed to York to say that Dr Laycock's qualifications were sufficient and he must get to work immediately.

Copy of Dispatch. Aug[ust] 161855

From Dr Simpson Edinburgh To Dr Laycock York.

All doctors are eligible. You must instantly collect certificates if fixed on competing not an hour should be lost several have already applied in all directions for them I am just returned from a visit to England and have no news yet. ${ }^{4}$

${ }^{4}$ Electric Telegraph Company message, J. Y. Simpson to T. Laycock, 16 August 1855. 


\section{Thomas Laycock}

After the usual greetings Dr Simpson looking about in the hall said to Dr Laycock. "Where is your bag?" Dr Laycock replied "at Mackay's". "Oh", he replied, "why leave it there? Your room is ready here these two days". Whereupon he ordered his man servant Tom Clarke, a well-known character, to go for Dr Laycock's bag to Mackay's.

Dr Laycock did not hesitate to accept this offer of hospitality from Dr Simpson. There were strong reasons why he should not. Independently of the more pleasant position in being domiciled in a private house rather than an hotel, there were strong reasons of policy. Dr Simpson was friendly to Dr Laycock as a candidate, as well as a personal acquaintance. Otherwise why did he write and telegraph? But he was bound by his position as a professor not to interfere-this he had explicitly stated. Now although this rule might apply to active canvassing, it could not apply to the hospitalities of private friendship, while such hospitality would silently prove that Dr Simpson had a warm interest in Dr Laycock's success, and by so much would influence any who could or might be influenced by a knowledge of that fact. Dr Laycock could not therefore throw away an opportunity which might clearly be worked to his advantage as one of the candidates. Again, Dr Laycock was wholly ignorant of the local modes of proceeding in cases of this kind; knew nothing of the spirit of the people; nor their habits, nor of the thousand minutiae which go to make up success, and which a man bent on success must carefully observe and attend to.

Dr Simpson was just the man to supply all this important information, and under no circumstances was it more attainable than while under his roof, and in contact with him at those moments of privacy which domestic life affords. As an example of this kind of information a trivial circumstance may be mentioned. Dr Laycock wore a black cravat, as is customary with the majority of physicians in England. Dr Simpson strongly advised him to call upon the town councillors in a white cravat and for this purpose Mrs Simpson supplied Dr Laycock with one of her husband's who wore them. This was the first time Dr Laycock wore white cravats professionally and of which he found it necessary to continue the use after his election. But they were not generally worn in Edinburgh; neither Dr Christison $\{b\}$, Dr Bennett, Professor Syme $\{b\}$ and others wore them; they were, in fact rather indicative of a turn for cant.

The candidates in the field or likely to be, were numerous. Dr Jenner of London, whose brother was an influential mercer in Edinburgh of the firm of Kennington and Jenner, Princes Street; Dr Neligan of Dublin; Dr W. T. Gairdner, son of a practitioner of influence; Dr A. Halliday Douglas $\{b\}$, cousin to Mr Francis Brown Douglas an influential member of the Town Council; Dr Bennett, Professor of the Institutes of Medicine in the University and one or two more. Drs Wood and Gairdner were Extra-Academical lecturers on the practice of physic and had already been candidates together with $\mathrm{Dr} \mathrm{H}$. Douglas for the Chair of Medicine in the University of Glasgow. All the Edinburgh candidates were therefore well prepared for the contest as Dr Alison's health had been declining for two years and the vacancy had been expected for so long a period. ${ }^{5}$

Dr Alison, brother to Sir Archibald Alison Bart, author of the History of Europe and son of the Reverend Archibald Alison, author of An Essay on the Beautiful and other works and who was an Episcopalian minister attached to St Paul's Church, York Place,

${ }^{5}$ Photograph of W. P. Alison, n.d. 


\section{Main Text}

Edinburgh, had been long connected with the University. He delivered the winter course of clinical lectures during the session 1821-22 in conjunction with Dr Graham $\{b\}$ this being his first performance of duty in the clinical wards. First occupying the Chair of the Institutes, on the resignation of Dr Home $\{b\}$ he succeeded to the Chair of the Practice of Medicine. He was a man of great popularity amongst students; was respected by his colleagues and adored by the poor to whom his benevolent kindness amounted almost to a monomania. Repeated attacks of epilepsy had enfeebled him, and were the more obstructive to the performance of the duties of his chair, because after each attack his intellect was more or less affected for a few days. It was also a painful circumstance that he had at least one fit while in the midst of a lecture at the College. Drs Bennett and Christison had occasionally taken his duty. The resignation of the chair although an event long expected, was anticipated more, however, by Dr Bennett for he looked upon the chair as the routine step of promotion from that of the Institutes and habituated himself to consider it as his by right, whenever it fell vacant. He told Mr Cathcart of the Royal Terrace (who told Dr Laycock) that in a year or two he should no longer take the five shilling fee, as he would then be Professor of the Practice of Medicine. And when he called at Dr Simpson's the day after Dr Laycock's arrival at Edinburgh he strutted up to the top of the table, where Dr Laycock was standing with that peculiar theatrical swagger which characterises him and is doubtless hereditary, saying "Well, I think I shall oppose you"-in a tone meant to be contemptuous. Dr Laycock turned round to Dr Priestley \{b\}, Dr Simpson's assistant and said sotto voce "Then I must get my sling and stone ready!"! This was indeed a heartfelt jest, for if the enterprise upon which Dr Laycock was engaged appeared to be almost hopeless at York, how much less probability of success did there appear when the number and position of the candidates for the chair were considered! Was it at all possible for a provincial physician, and a lecturer in an obscure school in England to compete successfully with any one of the local candidates? They had everything in their favour. Powerful local connexions, knowledge of the electors, experience in canvassing, would anywhere have been considered long odds, but in addition to all these they were Scotchmen, and Dr Laycock was an Englishman. And on this ground alone Dr Laycock could not anticipate success. It is true that a fair man declared the Town Council were only anxious on these occasions to put the right man in the right place. Such, we have seen, was the expressed opinion of Dr Simpson: such also of Mr Robert Chambers and others who wished to encourage Dr Laycock: but on the other hand few in England believed it possible for any other than a Scotchman to be elected to so high and prominent a position-so well marked and so strongly felt was the natural clannishness of the Scotch. This was the opinion of Sir John Forbes in sending a testimonial to Dr Laycock, breathed his wish for Dr Laycock's success in "Would you were a Scotsman!" but at the same time expressed his hopelessness. ${ }^{6}$

In war everything must be turned to account, however adverse or trifling, if success is to be assured-nothing that Dr Laycock could say would avail to alter the contemptuous opinion as to his prospects of success which by far the large majority felt, nor if that opinion could be altered, did it appear a step at all advisable, at that stage at least of the contest. The more he was feared, the more bitterly would Dr Laycock be opposed by all

\footnotetext{
${ }^{6}$ Letter, J. Forbes to T. Laycock, n.d. [27 September 1855] $\{\mathrm{t}\}$, and cutting of same from Testimonials.
} 


\section{Thomas Laycock}

the candidates. It was therefore policy as well as necessity to acquiesce in and even encourage the contemptuous opinion and appear as a hopeless candidate, not to be feared or dreaded by any. In the meantime the most assiduous efforts were determined on by him and an instant attempt was made to collect testimonials.

\section{(iii) Collecting Testimonials}

On 24 August Dr Laycock issued a formal address, announcing his candidature. ${ }^{7} \mathrm{~A}$ custom has prevailed in Scotland on the occasion of contests of this kind, which has only lately spread to England. The candidates collect testimonials of their excellence or fitness from every possible quarter, which they print and circulate freely not only amongst the electors but the general public. Thus there is a general interest excited as to the qualifications and probable success of the candidates, which extends into very unlikely quarters. This however is more particularly the case (or rather was) with the appointments to professors' chairs by the Town Council of Edinburgh, acting as patrons of the University. The University appears to have been originally a High School established by the burghers, and to have gradually developed into a university but retaining its connexion with the Town Council until the "Universities Act" of 1858 almost completely severed it. In this way it happened that the nomination to fifteen of the chairs was vested exclusively in the Town Council, principally in the arts and medicine; while six chairs, principally in law, were in their patronage conjointly with other public bodies in Edinburgh. The Crown appointed to ten chairs exclusively and to one (Botany) in conjunction with the Council. The Senate appointed to the Chair of Music only, and to the Chair of Agriculture conjointly with the Lords of Session and the Town Council.

Now the Town Council was a very heterogeneous body, but consisting as to the majority, of mercantile men, with a sprinkling of professional men. When therefore a vacancy was declared in the Senatus Academicus and testimonials as to the fitness of the candidates for the vacant chairs were sent to the thirty-three members of the Town Council, they found themselves in a difficult position, because their previous education and habits of life had certainly not qualified them to be judges of the merits of professors. This they fully acknowledged; but then, they alleged that they were only in the position of a jury at a trial in which matters involving important scientific questions were discussed and were therefore warranted in acting as a jury, on the evidence brought before them. They received therefore the testimonials sent to them as evidence into the validity of which they were bound to inquire, and to decide accordingly. What they desired to know, as in the case of the vacant Chair of the Practice of Physic was: in what opinion the candidates were held by those members of their common profession best competent to judge as to their attainments and powers of communicating knowledge. Such was expressed in the testimonials. Then they had to inquire into the position and capacity for forming a judgement of the testifiers; they had to have before them a statement as to the labours of the candidate in the special department in question; and by personal intercourse with the candidate himself to judge how far his appearance and manner fitted him for the appointment.

7 T. Laycock, First address, 24 August $1855\{\mathrm{t}\}$. 


\section{Main Text}

Now in the case of a vacancy in the Medical Faculty, it is obvious that the members of the Town Council would be guided in deciding as to the purely professional points by the opinions elicited from their own professional advisers, or other members of the profession, with whom they might have personal intercourse. Consequently the medical profession of Edinburgh had to be canvassed and influenced as well as the Town Council, and especially their good opinions as to the personal weight of the testifiers, regarding which the Town Council would be more particularly anxious. For it is very obvious that the recommendations strongly worded from a few of the highest and best ought to have more weight than recommendations from an unknown multitude.

And in this direction Dr Laycock saw that his being an Englishman and a stranger, might be turned to an advantage. If he could get first class testimonials to warrant the good opinion of the profession at large, he should at least have an audience unbiased by personal animosities and local prejudices, such as he knew by bitter experience must beset the path of persons struggling upwards, as doubtless all the local candidates had been, and that therefore full weight would be given to all he had to bring forward in his favour, by all except the most strongly prejudiced. If he began the contest without friends, he began it without personal enemies. Friends he could make, and the faster as he became more and more successful; enemies he could not have got rid of and the more he gained ground, the fiercer would be their opposition.

Dr Laycock lost no time therefore in seeking for testimonials. He had already published a series of them, only a year before when a candidate for the appointment of physician to the York County Hospital so that he was not wholly unprepared. Amongst them were testimonials from Sir James Clark, Sir J. Forbes, Dr J. Y. Simpson, and others. But they were much too few; on these occasions testimonials were poured in, literally by the hundreds. Thus Dr Bennett finally laid before the Town Council 280 documents of this kind. Dr Laycock, had therefore, to sit up a great part of the night writing off far and near, to everyone whose opinion could be reasonably asked, or who would be of weight. ${ }^{8}$

There was no small art to be exhibited in collecting these documents. It is of great importance that the testifier should express himself as to carry his readers with him, in the expression of his opinion. To this end an earnest style, free from conventionalism is the most important characteristic; but earnestness in expression is only attained through feeling in the writer. This need not necessarily be one of friendship: vanity, hatred to a rival, the mere love of encouraging the weaker side, the desire to patronise a rising man and similar feelings would equally serve to give earnestness and vigour to the language of the testimonial. Hence Dr Simpson counselled that in applying for "certificates" or testimonials, a list of Dr Laycock's works or papers on professional subjects should accompany the application and, together with that a specimen or two of the certificates already attained, as an example of the kind required. Hence also the necessity of constructing a catalogue of published writings; and as this was intended to influence the minds of both electors and testifiers, or writers of testimonials, its construction requires thought as to the best means of making it effective.

Then testimonials were required for particular objects, as for example to indicate the practical knowledge and extensive experience of the candidate, ${ }^{9}$ his varied reading, his

${ }^{8}$ Letter, T. Laycock to A. Laycock, 16 August $1855\{\mathrm{t}\}$.

9 Letter, J. Y. Simpson to T. Laycock, 22 August 1855 \{t\}. 


\section{Thomas Laycock}

moral worth; his freedom from taint of scepticism. ${ }^{10}$ As to the latter point Dr Laycock was already in some danger of check. He had published a paper "On the Function of the Brain" in the July number of the British and Foreign Medico-Chirurgical Review, and this was already accused by Dr H. McCormac of Belfast of "materialism". Such a cry was likely to be very efficacious with the Town Council. Dr Jenner of London was reported as a "Unitarian", and that the objection would be fatal to him. Agassiz had been named as the proper successor to Professor E. Forbes in the Chair of Natural History but Bailie Blackadder, a noted Free Church bigot, and an intense "Sabbatarian", had objected to him, that "he believed in three Adams, he understood". After all, they got a Unitarian in Professor Allman, but luckily his creed was never inquired into, and as when on a visit to Professor Balfour $\{b\}$ he attended church with Professor Balfour very regularly (the evangelical Mr Drummond's of "the Church of England in Scotland") his creed was never suspected, until after his election.

The style of application in some instances varied. Thus the annexed letter of application to Dr Brown Sequard (which was returned) shows the mode in which, even if his position [was] unknown to Dr Laycock, [testifiers] were addressed. ${ }^{11}$ Other examples may be seen in the letter folio [not located]. The mode in which these applications varied greatly and the replies illustrated the character and feeling of the writer. ${ }^{12}$ The replies from the medical baronets and other men of high professional position were perhaps the most characteristic.

Sir B. Brodie had for some time past made it a rule not to interfere in the appointment of professors in the Northern Universities, but without assigning a reason. ${ }^{13}$ Sir James Clark was spoken to at York when in attendance on the Queen on her journey to Balmoral. ${ }^{14} \mathrm{Sir}$ James very kindly took Dr Laycock close to the door of the Royal Carriage at the York platform, but he had not written anything, until Dr Bennett applied towards the close of the canvass to all those gentlemen who had given testimonials to Dr Laycock; and then he wrote with characteristic caution (which in him amounted almost timidity) to decline giving a testimonial to either. ${ }^{15} \mathrm{Sir}$ Charles Locock (unknown personally to Dr Laycock) was far more frank and readily and freely responded to Dr Laycock's request. Dr Watson, Physician to the Middlesex Hospital, and whose published Lectures on the Practice of Physic had given him a world wide reputation, strongly objected to the whole system of testimonials and [wished] physicians would refrain from seeking and offering them when candidates for public appointments. ${ }^{16}$ But then Dr Watson was in evident ignorance as to the details of the system of nomination and election followed out in Edinburgh in reference to the patronage of public bodies. For it is obvious that to refrain from this kind of evidence of fitness would leave the door open to all kinds of back-biting and slandering as well as intrigues. It was the publicity which the testimonial system received which in its turn constituted a security for fair play. Dr R. B. Todd (unknown personally to Dr Laycock as [was] Dr Watson) the editor of the Cyclopaedia of Anatomy and Physiology, and in the

${ }^{10}$ Letter, J. Y. Simpson to T. Laycock, "Tuesday night" [22 August 1855] \{t\}.

"I Letter, T. Laycock to B. Sequard, n.d. [c. 16 August 1855] $\{t\}$.

12 Letter, A. Jacob to T. Laycock, 18 August $1855\{t\}$.

13 Letter, B. Brodie to T. Laycock, 13 September $1855\{t\}$.

14 Engraving of J. Clark, Illustrated London News, 16 July 1870.

15 Letter, J. Clark to T. Laycock, 26 September $1855\{\mathrm{t}\}$.

16 Letter, T. Watson to T. Laycock, 21 August $1855\{\mathrm{t}\}$. 


\section{Main Text}

first rank of London physicians, expressed similar opinions, not however at so much length-but like Dr Watson he nevertheless wrote a useful certificate of his opinion as to Dr Laycock's fitness for the chair. ${ }^{17}$

Mr R. D. Grainger's reply was an example of the vulgarly cautious ${ }^{18}$ and Sir James Clark was of the gentlemanly cautious. If Mr Grainger had been one of the electors and had written in reply to a request for a vote, his reply would have been becoming. As it was, it only indicated an over-estimate of the importance of his opinion, which being really but one in a hundred at the most, was not worth much. Dr C. J. B. Williams wrote much in the same style, but with a little more of the savoir faire. ${ }^{19} \mathrm{Dr}$ W. B. Carpenter noted that Dr W. T. Gairdner had sent him a lithographed application and that he had told Dr Gairdner he had never received such a circular before. It was certainly a mark of both want of taste and want of tact. The broad routinism it hinted at, in the testimonial system must have shocked any man of ordinary conscientiousness.

Amongst the testimonials received by Dr Laycock were two which interested him very much. One was from Dr Richard Fowler of Salisbury, the other Jonathan Hutchinson, a physician in London. The last mentioned was a quaker, who had been a student at the York Medical School, and a member of Dr Laycock's class. It moved Dr Laycock and gratified him much to find such warm feelings of esteem expressed by an old student of his class, and the more because he had every reason to believe the expression sincere. ${ }^{20}$

Dr R. Fowler was an aged Physician resident at Salisbury. Dr Laycock had first made his acquaintance at a meeting of the British Association for the Advancement of Science, and had renewed it from time to time at similar meetings. He was a man of the highest natural endowments, and had attained the age of eighty-four with a singular freshness of feeling and judgement. He graduated at Edinburgh and was in his day one of the Secretaries of the Rights of the People, or some reforming association of that name. Although their proposed changes were of the most moderate character, only extending to a demand for the parliamentary franchise for Manchester, Leeds and other large towns, they were all held as little better than treasonable conspirators. Great, Dr Fowler told Dr Laycock on one occasion, was his surprise to see all their transactions in committee printed in a blue book! and which they in their simplicity believed to be inviolate secrets. When Horne Tooke was being tried, he and Astley Cooper (afterwards Sir Astley) had already packed and arranged for fleeing the country the moment the verdict of "guilty" (which was fully expected on all sides) was pronounced. Dr Fowler published a translation of Galvani's original researches, but almost the entire edition was destroyed by fire. He took a warm interest in various scientific questions, but his chief delight was in physiological psychology. His letter to Dr Laycock in reply to an application for a testimonial was as follows (Written from the meeting of the British Association for [the Advancement of] Science then held in Glasgow.)

"Sept 17 (1855) Glasgow Dear D' Laycock,

I had left Salisbury before your letter arrived and hoped to find you here. I have no

17 Letter, R. B. Todd to T. Laycock, 6 September $1855\{t\}$.

18 Letter, R. D. Grainger to T. Laycock, 23 August $1855\{t\}$.

19 Letter, C. J. Williams to T. Laycock, 3 September $1855\{t\}$.

${ }^{20}$ Letter, J. Hutchinson to T. Laycock, 17 September $1855\{t\}$. 


\section{Thomas Laycock}

hesitation in saying that I have not met with a more acute mind than (yours or) one more enriched with Physiological lore or who has a happier facility of communicating it with precision to others. These sentiments I will write in any form which you may think likely to produce a satisfactory effect. Ever my Dear Sir (or Dr)

Sincerely yours, Richard Fowler 49, West Regent Street, Glasgow".21

Professor Owen was written to, and was perhaps remarkable as the only one of all so addressed who failed in the courtesy to reply. A second letter was written to him at Glasgow, but it was doubtful whether he had made his appearance at the meeting of the Association or not. There could be no doubt that he had had the first letter delivered; otherwise, it would have been returned to $\mathrm{Dr}$ Laycock. Amongst the numerous correspondents in the country, whose letters may be seen in the letter folio, one is selected as indicative of the public opinion in England with reference to the feeling of the Scotch towards their own countrymen. It is from Sir Henry Cooper who was knighted by the Queen on occasion of her visit to Hull when he was Mayor of the Borough. He was an eminent physician in Hull. ${ }^{22}$

The last letter to be noted here is that of Sir Henry Holland. A community of pursuits had made Dr Laycock's writings known to Sir Henry Holland, so that when in $1845 \mathrm{Dr}$ Laycock happened to be in town, he requested Dr W. B. Carpenter to introduce Dr Laycock to him. This had finally led to a proposal from Sir H. Holland that Dr Laycock should review his Chapters in Mental Physiology in the Edinburgh [Review] and to which Dr Laycock had agreed. Sir H. Holland was a man of peculiar constitution, both mentally and physically. His handwriting is very characteristic of both. Thin with little muscular power apparently, subtle, cautious, intellectual; a courtier, ambitious, avaricious (so it is said), he had risen to a high reputation in both the medical and political as well as the literary world. To this latter probably his connexion with Sidney Smith helped, as he married Miss Smith. His testimonial was of great service to Dr Laycock. ${ }^{23}$

While testimonials were being collected according to the plan laid down, namely by direct applications sent to suitable persons together with examples of testimonials already given out, a list of the published papers and works was being made out. Fortunately, this had already been attempted in part when Dr Laycock was a candidate for the physicianship at the York County Hospital, otherwise the work would have been one of enormous difficulty to complete. As it was, the labour almost overwhelmed Dr Laycock, in as much as journals and works published during the last twenty years had to be ransacked for favourable opinions of Dr Laycock's papers, as well as for the papers themselves. Then the list had to be arranged so as to be presented to the electors and public in the most readable form. By 30 August, the catalogue was printed and ready for delivery. It contained the names or titles of 155 distinct essays and treatises with critical notices of many and occupied twenty octavo pages. A note stated that in addition to these there were about forty reviews, bibliographical notices and communications to medical periodicals, the titles of which, for various reasons, were omitted from the catalogue. The works reviewed amounted in the whole to 200 . Amongst the reviews omitted, was one on

21 Letter, R. Fowler to T. Laycock, 17 September 1855.

22 Letter, H. Cooper to T. Laycock, 20 August $1855\{\mathrm{t}\}$.

23 Letter, H. Holland to T. Laycock, 18 August $1855\{\mathrm{t}\}$. 


\section{CHRONOLOGICAL CATALOGUE.}

1. On the Acid and Alkaline reaction of the Saliva. A series of Clinical and Experimental Observations. London Medical Gazette.

* This is an interesting addition to the Physiological subject to which it refers, and is precisely such a communieation as the house-surgeons of hospitals are so well qualified to give, but which, we are sorry to say, they so marely do give." British and Foreign Medical Review, vol. v. p. 268.

2. Cases of Pulmonary Disease. 1. Periodic foetid Bronchitis. 2. Gangrenous Pneumonia.-Ibid.

3. On the Advantages of Water-Cushions for the bed-ridden. - London Medical Gazette.

This was the first introduction of the use of water-cushions, since become so general, for the siek.

4. On the Treatment of Spasm of the Glottis.-Ibid.

5. On the Pathology of Abdominal Tumors.-Ibid.

6. On the Iodide of Potassium as a substitute for Sarza.-London Medical Gazette.

7. On the Effects of Colchicum and Lytta applied externally.-London Medical Gazette.

8. Cases of Hysterical Ischuria. - Edinburgh Medical and Surgical Journal.

"On a former occasion we referred to this class of diseases, and expressed a wish that the subject were investigated in a philosophical manner. There is none more interesting in the records of physic. As contributing some new and authentic material, Mr. Laycock's paper will be useful; it is highly ereditable to his zeal and industry." - British and Foreign Medical Reciew, col. v.

9. 1. Cases of Hysterical Hremorrhages. 2. Hysterical Nervous Affections.-Edin. Med. and Surg. Jour.

10. On Anomalous forms of Hysteria, with new Views of their Phenomena.-Edin. Med. and Surg.Jour.

11. Analytical Essay on irregular and aggravated forms of Hysteria.-Edin. Med. and Surgical Journal.

"This is the continuation but not the conclusion of former papers on hysteria, and is marked by the same elaborate re.
1837.

Pathological Physiology.

Pathology and

Pract. Medicine.

1838 .

Pract. Medicine.

1838.

Pract. Medicine. 1838.

Pathology.

1838.

Pract. Medicine.

1838.

Pract. Medicine.

1838.

Special Pathology.

1838.

Special Pathology.

1838.

Special Pathology.

1838.

Special Pathology.

Figure 2: First page of the Chronological catalogue of the essays, reviews, and treatises . . published by Thomas Laycock, M.D., York, W. Sotheran, 1855. 


\section{Thomas Laycock}

Dickson the Chronothermalist and the final notice of Dr M. Hall in the twenty-third volume of the British and Foreign Medical Review, the peroration of which was written by Sir John Forbes. With a view to the stronger influence of the catalogue a particular arrangement was adopted. It is well known nothing is so irksome to the generality of men as a dry catalogue; it could not be expected therefore that either the Town Council or the medical profession could read such a work through and probably Dr Laycock's was in reality read through by comparatively few of those into whose hands it came. But the majority of the readers will read a footnote, or a paragraph in small print when it catches the eye. Acting upon this idea the subject of each work, or paper with the year in which it was published was printed in smaller type as a marginal reading-a "rubric" as Dr J. Y. Simpson with his presbyterian ignorance of episcopal terms, designated it. In like manner the favourable critical notices were inserted in smaller type between the titles of the essays \&c. In this way the perusal of the most important parts of the catalogue was much facilitated, and the effect of it greatly increased, for by glancing down the margin it was seen that every year from 1837 to 1855 produced its essays including an examination of every subject connected with medicine, while a glance at the laudatory notes showed how much they had been approved. The title of the work was a Chronological Catalogue of the Essays, Reviews, and Treatises in the Various Departments of the Theory and Practice of Medicine, including Pathology, Pathological physiology, Psychology, Hygiene, Medical Police, and Medical Ethics, Published by Thomas Laycock MD A Candidate for the Chair of Medicine in the University of Edinburgh. York 1855. A copy was immediately sent by post to every member of the Town Council, to the medical profession in Edinburgh, and to all persons who had given or were asked to give testimonials. An address to the Town Council accompanied it. ${ }^{24}$

The effect of this catalogue was instantaneous. Dr Laycock had not formed any adequate conception of the extent of his labours, much less those to whom the greater part was unknown. Its influence was that of an astonishing surprise, both in and out of the profession. Testimonials were more easily attained from every quarter, and breathed a more earnest and hearty spirit. Every one in England seemed ready to support the adventurer; in Scotland friends began to gather round Dr Laycock as he now had been represented, and rivals felt for him more respect, although as yet, strong in their local influence, and in the sufficiency of local prejudices to keep out Dr Laycock they saw only in each other the rivals to be dreaded, and therefore little opposition was experienced by Dr Laycock.

\section{(iv) The Canvass}

The day after his arrival at Edinburgh (17 August) Dr Laycock began his canvass of the councillors and all persons likely to influence their decision as to the selection of a successor to Dr Alison. His first step was to have a card printed which should announce his name and intentions to the electors. ${ }^{25}$ To this end he called at the first lithographic printing office he met with and this happened to be William Forrester's in Hanover Street who printed the card.

24 T. Laycock, Second address, 30 August $1855\{\mathrm{t}\}$.

25 T. Laycock, Candidate's card for the Chair of Physic $\{\mathrm{p}\}$ and a former one for the office of Physician to the York Dispensary. 


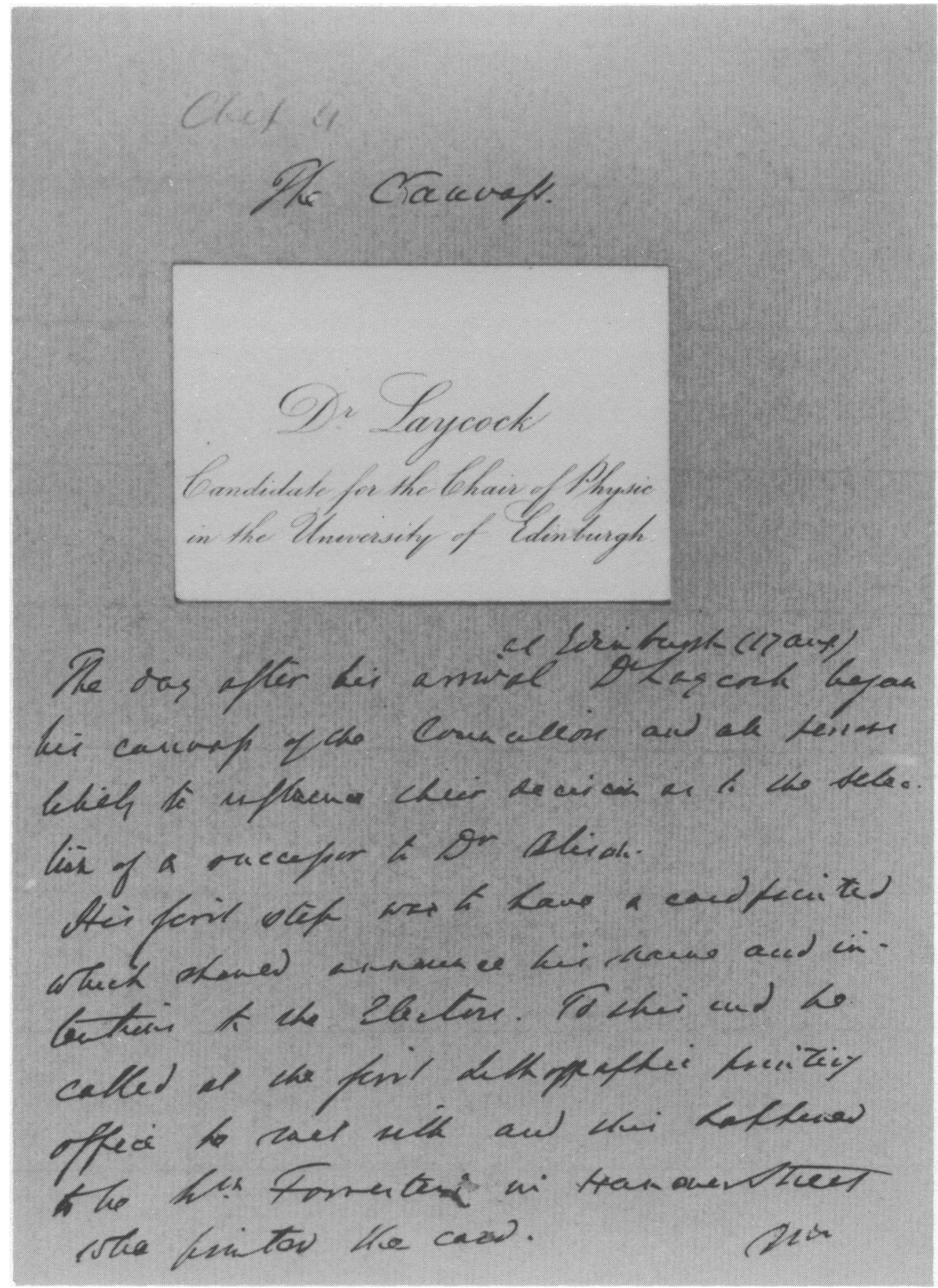

Figure 3: Page of the 'Account' showing Laycock's Candidate's card. 


\section{Thomas Laycock}

Mr Forrester's men being slow in their proceedings Dr Laycock found it necessary to quicken them by an appeal to Forrester himself. To his surprise he found that the latter was one of the electors, being a member of the City Council. Dr Laycock's proceedings in sharpening his movements had no unfavourable effect on the councillor, but the contrary. A bluff, stout Anglo-Saxon, he evidently liked the hearty earnest manner with which he was met and was thenceforth Dr Laycock's fastest and firmest supporter.

Having got the card printed Dr Laycock set forth to call upon the electors, armed with a list containing their names, addresses and occupations with which Dr Laycock was supplied by Dr Priestley. ${ }^{26}$ In this way he spent several hours during the business portion of that day and the next and returned to York on Sunday, 19 August. ${ }^{27}$ Having prepared and passed his testimonials and catalogue through the press and the public, Dr Laycock returned to Edinburgh on 10 September to prosecute his canvass. Things had taken a more settled form during his absence and the men and things to be overcome were more clearly seen. For some time past there had been great doubt whether Dr Christison, Professor of Materia Medica, would not come forward; his friends had, indeed, authentically announced that he would accept the chair if it were offered to him. The principal supporters and promoters of this move were the friends of Dr Douglas Maclagan, Lecturer on Materia Medica in the private or Extra-Academical School, and a private friend of Dr Christison's, for it was intended that in case the latter was promoted to the Chair of Physic, Dr Maclagan should be an early candidate for the vacant Chair of Materia Medica with every prospect of success. Dr Laycock had heard of this from various quarters and had even been advised to withdraw from the competition in face of such a proposition.

Dr Christison had attained to an eminence in the medical and scientific rather in virtue of his pretensions than his performances, and was no doubt thought the most suitable successor to Alison by many. And his vanity would have been much flattered by the offer of the chair on the part of the Town Council, for he felt in common with others that the occupant was the primus inter pares of the Medical Faculty. Dr Christison's self-esteem was great. It has been hinted, indeed, that George Combe drew his picture when describing the influence of the "organ" on the features. "When the organ of Self-Esteem predominates", he says, "in size over all the other organs, it gives a cold, selfish, imperious air to the individual. He carries his head high, his look is full of disdain, and his walk and speech are solemn and pretentious", (George Combe, A System of Phrenology, vol. 2, pp. 75-6). But it was not to be expected that the other candidates would acquiesce in this arrangement. Drs Wood, Gairdner, and Douglas would necessarily object to it altogether as precluding the possibility of their being elected. Their friends therefore asked why could Dr Christison claim an exemption from the general rule of competition? and insisted that he should take his place among the other candidates. This they knew he would never do; for his self-esteem would not allow him to stoop so low (as he thought) to ask a favour from the Bailies and Councilbodies[?] of the Town Council, nor to risk the humiliation of a rejection. On the other hand his friend and colleague Mr Syme, Professor of Clinical Surgery, had a plan for bringing his own friend Professor Sharpey of the University College, London back to Edinburgh, as successor to Professor Bennett in the Chair of the

\footnotetext{
26 Letter, T. Laycock to A. Laycock, 17 August $1855\{\mathrm{t}\}$.
}

27 Letter, T. Laycock to A. Laycock, 18 August $1855\{\mathrm{t}\}$. 


\section{Main Text}

Institutes or Physiology, on his promotion to the Chair of Physic. So that there was a rivalry between the friends of Maclagan and Sharpey for the reversion of the respective chairs of Bennett and Christison, independently of the rivalry between the two professors. It was not difficult to find one or two members of the Town Council who would insist upon an open competition under these circumstances, for the friends of all the avowed candidates, and also of the two reversion-candidates agreed in opposing Dr Christison, and knew that it was a unanimous vote alone, which could warrant the Town Council in offering the chair to him. Dr Christison therefore withdrew his pretensions early in September, alleging as a reason that he was busy[?] and could not be prepared to give a course of lectures on the practice of physic. In reality he knew quite well (or at least Dr Bennett's friends convinced him) that there would be no chance of the compliment he so much desiderated being paid to him. ${ }^{28}$ The field was then left free for competition amongst the candidates junior to him. ${ }^{29}$

The other candidates might be classed as junior and senior. Drs Wood and Bennett were contemporaries and fellow students, Dr Wood being somewhat the junior; Dr Laycock and Dr Bennett were almost exactly of the same age-there being perhaps not a year's difference between them. Dr W. T. Gairdner and Dr A. H. Douglas were more nearly of an age; the former the junior, he had in fact been a pupil of Dr Bennett's. It was not difficult to estimate the respective strength of the candidates as to local "backings". Dr Bennett occupied decidedly the foremost place of strength. He had already the prestige which attaches to a professor; he had been an earnest labourer in the field of medicine for many years and had acquired an excellent reputation as an investigator; he was in the customary line of promotion as the step had normally been from the Chair of the Institutes or Theory of Medicine, to the Chair of the Practice; and he had the active support of his colleagues, especially of both Dr Christison and Professor Syme.

Next after Dr Bennett, Dr Wood was the most powerful. He had the Free Church as his supporters, and this was strongly represented in the Town Council. That differences of a sectarian character would influence the opinions of the electors was confidently believed from the experience already had as to the Free Church influence in the elections to the chairs of the University. Professor Macdougall being a Free Church minister had been elected as the successor of Wilson (Christopher North of Blackwood) to the Chair of Moral Philosophy and Political Economy. He had some of the profession too, to back him, especially those of the College of Physicians, to which he was Secretary. Dr Bennett was unpopular with the profession.

Dr W. T. Gairdner divided with Dr Wood the influence of the Extra-Academical School in which they both were lecturers on the Practice of Physic, but Dr Gairdner's father was treasurer of the Royal College of Surgeons, and upon the whole, therefore, his influence preponderated over that of Dr Wood. Dr Gairdner was distinguished, also, far more than Dr Wood for the number and variety of his contributions to medical science, for having been first Pathologist and then Physician to the Royal Infirmary, he had had favourable opportunities for research and had turned these to good account. He divided sectarian influence with Dr Bennett, inasmuch as the persons with whom he was connected

28 Letter, T. Laycock to A. Laycock, 11 September $1855\{t\}$.

29 Letter, T. Laycock to A. Laycock, 13 September 1855 \{t\}. 


\section{Thomas Laycock}

religiously and politically were opposed to the religious radicalism of the Free Church party, and leaned to the old Whig party constituted of the educated and higher classes of Edinburgh, and which had some of its best representatives in the University. A few months before Dr Gairdner had abandoned the Unitarian congregation worshipping at St Mark's, Castle Terrace Edinburgh, where he played the organ, ostensibly on the ground of some pecuniary differences with the minister Mr Gordon, but, really it was believed, in view of the prospectiveness of the impending election to the Chair of Physic, knowing that a professed Unitarian would have no chance with the electors. (See Dr J. Y. Simpson's letter of Tuesday, 22 August) [n 9]. Dr Gairdner joined the congregation of Dr Robert Lee, Professor of Biblical Criticism, who was himself held to be somewhat heterodox, both in regard to "rationalism" and prelacy.

Dr A. H. Douglas had been Physician to the Infirmary and had given clinical instructions there. His contributions to practical medicine were not numerous but solid. He was a Free Church man, but had no sect or party to back him, all these being already engaged on the side of the other candidates. His only solid support was his Cousin $\mathrm{Mr}$ Francis Brown Douglas, a wealthy member of the Town Council.

The personal qualifications of these four candidates varied considerably. Dr Douglas was without question the most gentlemanly and most fitted by moral qualities for the chair. He was however deficient in mental vigour. Dr W. T. Gairdner was not devoid of good feeling, but he was somewhat egotistical and assuming, and had not that good tone of thought or action which the constant association with the well-bred supplies. He was said to be liked by his students more as a teacher than a man.

Dr Wood was still less popular than Dr Gairdner. He was considered to be of a litigacious, discontented temper, mischievous, vindictive. In the Medical Times and Gazette a letter occasionally appeared from "Our Edinburgh Correspondent" which contained pretty provoking impertinences regarding physicians and surgeons in Edinburgh, and of these Dr Wood had the reputation of being the author. He had a copious flow of language, and was felicitous in his expressions; and if he had known when to stop he would have been a successful speaker. Unfortunately he had a word diarrhoea, and when once he began would pour out an incessant stream of words in a reedy nasal tone to the utter weariness at last of his audience.

Dr Bennett was the most unpopular of all. He had no grace of any kind-religious, moral, aesthetic. It was said that he arranged the abortions of his mistress on the mantelpiece, when he lived in Paris, and exhibited them to his fellow students. He was reckless in his statements, greedy of money and fees, coarse and uncourteous in his language and conduct and much better fitted for the stock exchange and the society of "bulls" and "bears" than scientific men. His reasoning powers were defective, and it was not thought his observing powers were accurate. He had all the energy which belongs to an impulsive nature more cunning than subtle; and his mind little cultivated by education in at least the higher branches of knowledge. He could sing a good song and was a fluent persuasive speaker, partly from the natural gift of a good voice, and partly, perhaps, from early habits - for his father was a country actor, and manager. Mr Brewster who died at Houghton Le Street near Darlington told Dr Laycock that he once heard manager Bennett sing a coarse song adapted to country taste when acting at Richmond in Yorkshire. Dr Bennett could sing a comic song well, and had a marked theatrical strut. 


\section{Main Text}

Opinions varied much as to the success of the candidates. By some, Dr Wood was thought not to have a chance: others thought the contest was between Wood and Gairdner, or Bennett and Gairdner. But no mention was made of Dr Laycock's prospects until the first batch of testimonials began to be read and talked about. They were said by some to have "come upon the town like a bomb shell". They were given to him by his neighbours, members of the Institute at York, Professor Phillips, Reverend William V. Harcourt, the students of the York Medical School, the Lecturers in the School, and by Physicians and Surgeons of the highest rank and most distinguished reputation at home and abroad. All this Dr Laycock could honestly say in the address which he prefixed to the testimonials; and while it enhanced their value, it pleased the givers. ${ }^{30}$

The publication of the catalogue and testimonials produced a powerful effect in as much as together they illustrated a point in Dr Laycock's character of great importance. The one showed the general and professional public how unostentatiously Dr Laycock had been labouring for many years for the advancement of all branches of medical science; and this was in favourable contrast with Drs Bennett, Wood and Gairdner, who in anticipation of the vacancy, had been labouring as ostentatiously as possible. The other showed that in spite of this quiet method of labour, Dr Laycock's merits had not escaped the notice of his contemporaries. Nothing indeed could be more astonishing to Dr Laycock than the zeal and energy with which his cause was advocated and his merits declared by those to whom he applied, for he had no reason to think his reputation had extended so widely. Dr Dickinson and Dr McNicol laboured in Liverpool, to secure a joint testimonial from Liverpool. Dr Maunsell and Dr Jacob supported Dr Laycock in Dublin; Mr Keyworth, Mr O. A. Moore, Mr Charlesworth and others in York; while leading men in London and the great provincial towns contributed their aid.

The feelings excited in Edinburgh were various as the men. Some saw in Dr Laycock an individual who would infuse "new blood" into the University. His labours exceeded those of the other candidates not only in numbers but in extent and importance. Which of them, for example, had so efficiently contributed to the progress of public hygiene? Which had laboured so successfully for the advancement of a practical science of mind? It was not simply in the field of pathology and the practice of medicine that Dr Laycock had laboured with a success equal at least to any of his competitors; but unlike them, he had extended his inquiries into every department of the vast continent of medicine. These honestly supported Dr Laycock from the simple conviction that he was the best man, without commingling inferior motives. Amongst these might be mentioned Mr Robert Chambers, Mr D. R. Hay author of The Principles of Beauty \&c. Mr R. Cox, Dr Macfarlane, an old retired physician formerly resident medical adviser to the Duke of Atholl, Dr Priestley, Mr W. S. Carmichael $\{b\}$.

Others supported Dr Laycock with the conviction that he was in every way suitable for the appointment, but also with the hope that, in securing his election, they would defeat the long-cherished hope of one or other of the candidates. Personal hostility was in fact the ruling motive rather than an earnest wish to benefit the University and the profession, although it would be altogether unjust to deny that they had no better motives. It was simply the ruling motive - that which intensified their zeal in support of Dr Laycock. Mr

${ }^{30}$ T. Laycock, Third address, 7 September $1855\{\mathrm{t}\}$. 


\section{Thomas Laycock}

Lizars $\{b\}$ the surgeon was an example of this. He knew that Professor Syme was anxious for Dr Bennett's election, that he might introduce his friend Dr Sharpey into the Chair of the Institutes. And this was enough for John Lizars. They had been life-long antagonists: had fought in both the academic hall, and the courts of law with varying fortunes, and they never lost an opportunity of annoying each other. So soon, therefore, as Lizars heard of $\mathrm{Mr}$ Syme's scheme, he took measures to baffle it. Neither Wood nor Gairdner, nor Douglas, were men he could support. He consequently sought out for another candidate, and this he hoped he had found in Dr Sibson of London, a former pupil of his own. Dr Sibson, however, declined to engage in the strife under Lizars's auspices, and the latter after reading Dr Laycock's testimonials concluded he had found a man worthy to be backed against the others. ${ }^{31} \mathrm{He}$ committed at once with his friend Dr John Renton \{b\}, a member of the Town Council, who also became at once an active supporter of Dr Laycock, and was the first to declare himself. ${ }^{32-33}$ Dr Renton was subsequently the proposer of Dr Laycock in the Town Council.

The majority of the public and especially of the Town Council held aloof, however, from any decisive expression of opinion, as to the various candidates and were not expected to give any until within a few days of the election. Dr Laycock saw clearly that his present business was not so much with personal friends and enemies (as was the case with the other candidates) but with that deeper Scottish feeling, which would not willingly give so important a chair in the national university to a provincial Englishman, however well qualified and however strongly recommended. Against this therefore, for the present he directed all his best efforts when canvassing, in the mean while justifying himself in the minor points. ${ }^{34}$

Dr Laycock was most agreeably disappointed in the reception he met with when he called upon the various members of the Town Council. He had already had experience of elections of this kind having contested successfully for the appointment of House Surgeon to the York Hospital in February 1836, after a long struggle, and again unsuccessfully for the appointment of Physician to the same institution in the summer of 1854. The tone of feeling as well as of conduct was far better with the councillors than the respectable Governors of the County Hospital: the sentiments and manners more dignified and the reception of the candidate more courteous. To this rule there was the single exception of an old man of the name of Millar, a watchmaker on the North Bridge.

In his interviews with the electors, Dr Laycock aimed mainly at a counteraction of local prejudices and influence. He apologised for prolonged interviews by alleging that he was so complete a stranger, it was only in conversation that the electors could form any estimate of his personal qualifications; he also avoided any solicitation; accepting the theory that they were a jury, he appeared in the character of an "advocate" bound to set forth the strong points in his own case, and to indicate any sources of fallacy by which their judgement, as jurymen were likely to be influenced. He said nothing in the least degree disparaging to any of the other candidates, knowing nothing would be more

31 Letter, J. Lizars to T. Laycock, 20 September $1855\{t\}$.

32 Letter, A. Laycock to T. Laycock, 23 September 1855 [on verso of 33 below] $\{t\}$.

33 Letter, J. Lizars to T. Laycock, 22 September $1855\{t\}$.

34 Letter, T. Laycock to A. Laycock, 12 September $1855\{t\}$. 


\section{Main Text}

impolitic or in worst taste; and feeling satisfied that any faults or defect in them would be sharply looked after and exposed by each other or by their respective partisans.

Dr Alexander Wood had already published a testimonial given to him by Dr Laycock when he was a candidate for the Chair of the Practice of Medicine at Glasgow; this some of the electors referred to with the object of eliciting Dr Laycock's opinion as to the merits of the other candidates. Dr Laycock's reply was that the testimonial honestly expressed his opinion as to Dr Wood's fitness and that he would be glad to write the same for the other candidates for all [of] whom he had a great respect. He found, however, that disparaging remarks were made regarding him, by two of the others. It was reported to him by $\mathrm{Mr}$ Francis Richardson that Dr Wood had sneered at him, as the holder of a German degree only, and Dr Bennett propagated the slander already used by Dr Simpson of York that Dr Laycock was of a quarrelsome temper. This slander had met Dr Laycock on various occasions; as for example, when he was engaged to be married it was conveyed to the ears of his wife's friends; and when he was a candidate for the physicianship of the York County Hospital (as Dr Simpson acknowledged to Dr Laycock) Dr Thomas Simpson spread it largely amongst influential governors, so as to prevent his election. It has already been shown how the same slander was made available in excluding Dr Laycock from the York Medical Society: it is right to add that it was also successfully used to exclude him from the local scientific converzationes of the Yorkshire Philosophical Society. Happily it had no effect on the town councillors of Edinburgh, but the contrary. They looked upon the slander as a proof that Dr Laycock's success at York had excited the envy and hatred of his rivals there. They agreed that if Dr Laycock had been a harmless, useless being he would have excited no hostility, and as his conduct and manner showed him to be wholly free from any such spirit of disparagement, the slander was looked upon as wholly groundless. The great work of the canvass was not, however, limited to the candidates themselves; their friends avowed, or concealed, took an active part. To this portion of the struggle a special chapter may be devoted. Having completed his canvass Dr Laycock left Edinburgh for York (where he was having further testimonials printed) on 19 September, and left the field clear to the candidates and their auxiliary forces.

\section{(v) The Committees and Friends of the Candidates in Edinburgh}

The long period (seven weeks) which elapsed between the declaration of Dr Alison's resignation and the day of election gave ample time and opportunity for the friends of the candidates to bring all possible influences to bear upon the election. Dr A. H. Douglas made very little effort after the first few days and his friends were hardly heard of. Dr Gairdner's were more active but if organised (as they probably were) went about the work of canvassing very quietly. He never, however, secured more than three or four votes.

Dr Wood had a large committee, which held regular meetings and planned the canvass very much as if it was a contested parliamentary election. Every means of influence was sought out and brought to bear upon the electors to the great disgust of some if not many. Mr Clark of Glen Ross, grocer, told me that he was besieged by persons who brought groceries of him, as if that was a reason why he should give up his judgement to them. ExBailie Tullis said that a half-pay captain had been at him because he was his neighbour and tenant to solicit for Wood, and he was instigated by a lady who was a patient of Dr Wood's. 


\section{Thomas Laycock}

Nothing could be more offensive than these solicitations to men who believed their sole duty was to elect the fittest man irrespective of all private considerations, for they not only implied the Town Council was incompetent to judge, but that he [Tullis] was dishonest, and would yield to interested solicitations what was to be decided strictly on equitable grounds; in short their method was a gross imputation upon the whole body in as much as it practically assumed they were unjust judges. Dr Wood's committee was, therefore, not so useful as he imagined.

Dr Bennett was strongly supported by Dr Christison, by [James] Simson $\{b\}$ (his neighbour in Glenfarglas Street), Professor Syme, and the University party generally. He had also the support of Professor Simpson as he believed. Dr Laycock had no committee, nor did he trust his plan of the campaign to anyone. He accepted help and advice from any quarter, Dr Simpson had already rendered indirect assistance by taking Dr Laycock into his house, and leaving a table in his back parlour in Queen Street very much at his service. There Dr Laycock was assisted by Dr Priestley (Dr Simpson's assistant) Mr William S. Carmichael, surgeon in Northumberland Street, and Dr Simpson himself.

Mr Carmichael had been in previous years, Dr Simpson's assistant; he was cousin to Mrs Simpson, Mrs Simpson's mother being sister to his mother. He was a man of warm enthusiastic temperament and took up Dr Laycock's cause very warmly from the first. His relations with Dr Simpson were such that he had got the name of "Simpson's Jackal". His obligations to Dr Simpson were of a pecuniary character, for Dr Simpson had advanced money to relieve him from serious liabilities incurred during the mania for railway speculation. ${ }^{35}$ He was an excellent partisan, active, shrewd, always picking up information (being an imperturbable questioner) and quick in turning circumstances to account. He was somewhat too fussy and required a little checking, but this was rather a good fault. He evidently delighted in the work itself. ${ }^{36}$

Dr Priestley was a native of Leeds. ${ }^{37} \mathrm{He}$ was a grandson of Dr Priestley the physicist and philosopher but his friends were Wesleyans and he had a brother in the Wesleyan University. ${ }^{38}$ As Dr Laycock's father and only brother were Wesleyans, there was a bond of sympathy, in addition to the predilection one Yorkshireman feels for another-in the Scottish way. ${ }^{39} \mathrm{He}$ was engaged to be married to Miss Ella Chambers one of the twin daughters of Mr Robert Chambers, and as the latter took an interest in Dr Laycock's success Dr Priestley naturally went with his intended father-in-law. He was very cautious however, in showing openly any activity in Dr Laycock's favour. ${ }^{40}$

Mr Robert Chambers was already known to Dr Laycock. ${ }^{41}$ They had first become acquainted at the meeting of the British Association for the Advancement of Science when held in York. When Dr Laycock and his bride visited Edinburgh in 1848 (May) Mr Chambers kindly showed them the antiquities of the Old Town, and Mrs Chambers accompanied them to Roslin and Hawthornden. He had observed a confirmation of Dr

35 Letter, W. S. Carmichael to T. Laycock, 20 September $1855\{\mathrm{t}\}$.

${ }^{36}$ Letter, W. S. Carmichael to T. Laycock, 21 September $1855\{\mathrm{t}\}$.

${ }^{37}$ Letter, W. O. Priestley to T. Laycock, 20 August $1855\{\mathrm{t}\}$.

38 Letter, W. O. Priestley to T. Laycock, 28 August $1855\{\mathrm{t}\}$.

39 Letter, W. O. Priestley to T. Laycock, 29 August $1855\{\mathrm{t}\}$.

40) Letter, W. O. Priestley to T. Laycock, 30 August $1855\{\mathrm{t}\}$.

41 Letter, R. Chambers to T. Laycock, 27 August $1855\{\mathrm{t}\}$. 


\section{Main Text}

Laycock's Law of Vital Periodicity in the parallel development and contemporaneous diseases of his twin daughters and had noticed the subject in his Journal. ${ }^{42} \mathrm{He}$ was not of a warm enthusiastic temper, but a solid sound friend and quietly laboured in Dr Laycock's interests but so as not to give offence or excite opposition. ${ }^{43}$

Dr J. Y. Simpson played, however, the principal part in Dr Laycock's election. ${ }^{44} \mathrm{Dr}$ Laycock was resident in his house while in Edinburgh canvassing and acted about wholly under his advice as to getting testimonials, printing them, and distributing them. He had ample experience as to the details of a contested election of this kind having only obtained his own chair by a majority of one, after a long and severe contest with Dr Kennedy of Dublin, backed by all the University influence. His advice was therefore very valuable. The difficulty in his case was to determine whether he was really anxious for Dr Laycock's success. In his first letter to Dr Laycock he said the professors would not interfere and yet there was reason to think he was an avowed friend of Dr Bennett. On the other hand, he gave Dr Laycock strong grounds for thinking he was his warm friend and was only prevented from openly acting in his favour by a feeling of propriety. His sending for Dr Laycock at all was significant; when Dr Laycock thanked Dr Simpson for thinking of him he replied "Oh! indeed, I've been always thinking of you". (See Dr Laycock's letter 17 August 1855) [n 26]. In the beginning of September he came over to York on a visit to Dr Laycock, [who] took him to Castle Howard where he introduced him to Lady Mary Labouchere and others of the Howard family then resident. On this occasion the fountains (although Sunday) were set playing. Dr Laycock lunched with the family. In returning they went round by Faston and looked into the window of the Village Church where Sidney Smith used to officiate while service was going on. The next day they went to Hull, Dr Simpson wishing to see the method used by the oilmen for the purification of oil, as he had a scheme for obtaining oil from Barbadoes Petroleum. It was curious to see how he endeavoured to cajole the manufacturers into giving him information under the innocent pretext of professional curiosity, and what pleasure it was to him to succeed at all. On this occasion he was most assiduous in pushing the printing of the testimonials, and in arranging and concocting them. Before he visited Dr Laycock in York, Dr Simpson corrected the proof of Dr Laycock's address to the electors, ${ }^{45}$ and in writing to him a letter of counsel from Arniston, said "I do think your prospects brighten". (Vide letter of 22 August 1855) [n 9].

When Dr Laycock returned to Edinburgh to canvass after the distribution of his catalogue and first batch of testimonials Dr Simpson invited the other candidates (all of whom were present except Dr Bennett) and a number of professional gentlemen to meet Dr Laycock at dinner. After the people had left for the most part and four only remained, when Dr Laycock remarked "I like Gairdner better than Wood and Halliday Douglas better than both"-Dr Simpson exclaimed "and we like you better than all". And on the same day (in the morning of 13 September) Dr Gairdner told Dr Laycock that Dr Simpson had given up Bennett and was recommending Dr Laycock all he could. Thus in private and

42 Letter, R. Chambers to T. Laycock, 7 September $1855\{t\}$.

43 Engraving of R. Chambers by D. J. Pound from a photograph by Mayall, 1860.

44 Photograph of J. Y. Simpson, $1860\{\mathrm{p}\}$.

45 Proof of First address, with corrections by J. Y. Simpson and T. Laycock, 21 August 1855 \{t, p\}. 


\section{Thomas Laycock}

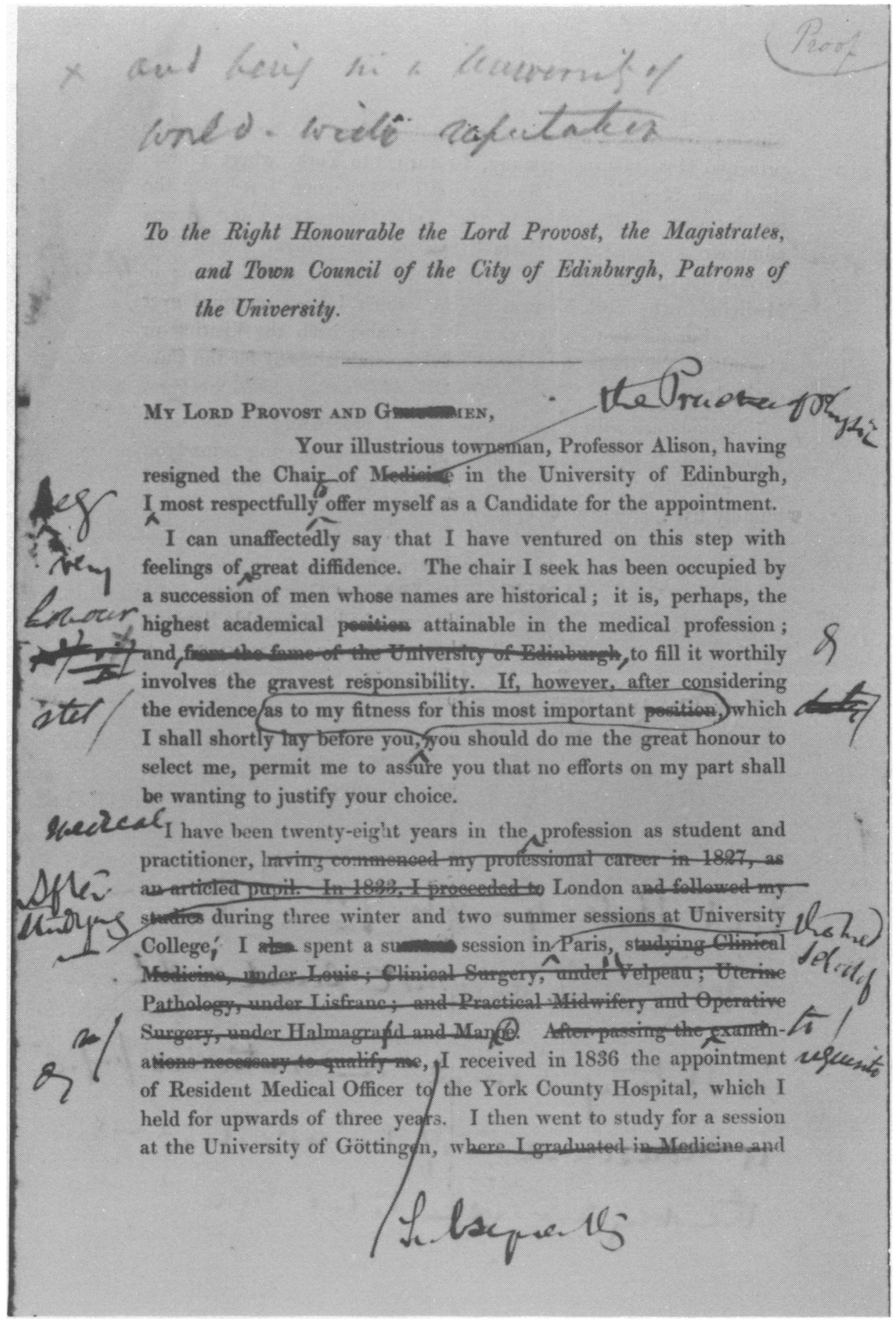

Figures 4(a) and (b): The corrected proof of Laycock's First address. 
Main Text

After visiting the principal Hospitals in Germany, I returned to York, where I proctied both Medicine and Surgery until 1842, when I received the appointment of Physician to the York Dispensary, and was

em a admitted a Licentiate Extra-Urben of the Royal College of Physicians of London. In 1846, I was elected to the Chair of Medicine in the York Medical School, which I have occupied ever since. Far ho hat eight years, I have also been the Visiting or

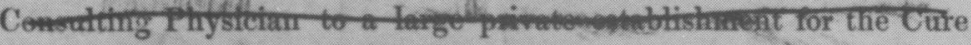
of the Insane. -

In compliance with the usual method of proceeding on occasions. of this kind, I shall take an early opportunity of placing before you such evidence of my fitness for the "appointment I seek as will, I humbly trust, obtain your approval.

I am, with the greatest respect, Mr Lord Provost and Gentlemen, Your very obedient humble Servant, THO. HAYCOCK.

York, 21st Aug., 1855.

Pout that y- gel qua Degree.driven. Ad does nut Rand well.

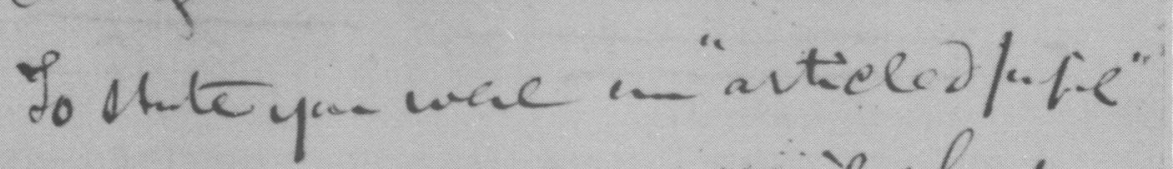
is reasende so of mo ai nil; the very revise troubles

77

https://doi.org/10.1017/S0025727300071660 Published online by Cambridge University Press 


\section{Thomas Laycock}

in correspondence his manner and language gave the strongest indications that he had the warmest interest in Dr Laycock's success, watching and warning at every point. ${ }^{46}$

But on the other hand there were hints and indications that Dr Simpson was not wholly sincere, and in particular that he was helping Dr Bennett. Several of Dr Laycock's friends in Edinburgh significantly asked him whether he was quite sure Dr Simpson was sincerely friendly to him? It was also rumoured in York that Dr Simpson was not really Dr Laycock's friend but Dr Bennett's. Mr Keyworth in particular asked information on this point more than once. And once or twice Dr Simpson got very warm in defence of Dr Bennett, especially on the occasion Dr Bennett's conduct was discussed in getting $\mathrm{Mr}$ [William Worthington] assistant to "Professor" Dick of the Veterinary College to make vivisectional researches for him and claimed the merit of them in a paper read to the Medico-Chirurgical Society. And during the final struggle Dr Simpson one day swept up the final proof sheets of Dr Laycock's testimonials from his table and carried them off to Dr Bennett that he might write to all those who had written testimonials for Dr Laycock. That this was done by Dr Bennett is proved by the tenure of the letters received from Sir James Clark (see letter of 26 September 1855) [n 15], Dr Symmonds of Bristol, and others (see Folio letters)[not located].

When Dr Laycock was told by hints that Dr Simpson's good faith to him was doubtful he could only reply that as Dr Simpson had stated in the outset none of the professors either could or would interfere, he accepted any assistance which Dr Simpson rendered as more than he bargained for, and was grateful accordingly: that if Dr Bennett was assisted by Dr Simpson he was at liberty to please himself, \&c. On the other hand he attempted to explain Dr Simpson's conduct by the hypothesis he wish[ed] to have a second candidate to oppose Dr Wood in case Dr Bennett was not strong enough to carry his election against Dr Wood. In this Dr Laycock had a particular tactic in view.

Dr Simpson was not left uninformed as to the hints Dr Laycock received regarding his conduct nor as to the replies Dr Laycock gave. He thought it right that Dr Simpson should not be kept in ignorance. Dr Wood was exceedingly objectionable to Dr Simpson and others at this time for reasons already stated and was strenuously opposed by him and them. Yet so well Dr Simpson could conceal this hostility that he asked Dr Wood to dine with him as a friend. It may be as well to state here, that subsequent disclosures showed Dr Simpson had been guilty of great duplicity towards Dr Bennett at least, if not to Dr Laycock.

On 2 November 1858, when the municipal elections were about to take place, Dr J.H. Bennett appeared amongst the electors (an unusual circumstance) and proposed a candidate for St George's Ward-Mr Robertson. On that occasion he took occasion to ventilate all his grievances against the Town Council and others, and amongst the latter attacked Dr Simpson, whom he charged with having received Dr Laycock into his house during the canvass and though he (Dr Simpson) pretended to be on his (Dr Bennett's) side, did all he could in private to damage his claims. This speech was published in all the newspapers ${ }^{47}$ and Dr Simpson found it necessary to write a letter to The Daily Scotsman in reply in which he gave the most unqualified denial to Dr Bennett's assertions, whose

46 Letter, T. Laycock to A. Laycock, 14 September $1855\{t\}$.

47 Press cutting, Daily Express, 3 November $1858\{t\}$. 
Main Text

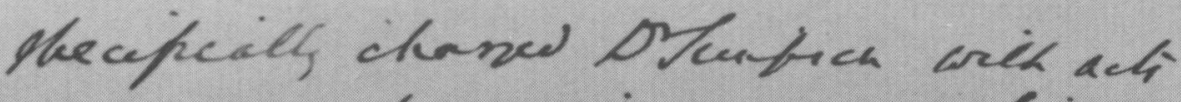

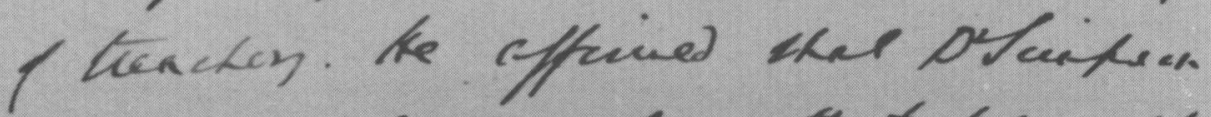

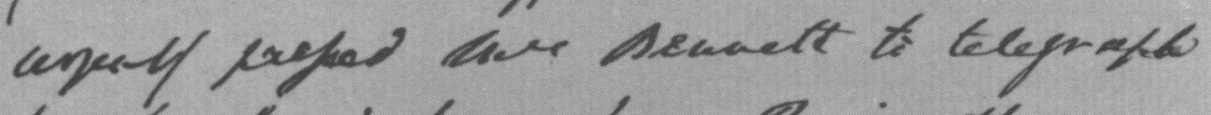
Ler hurtand hame hom Pravi. ther cieng

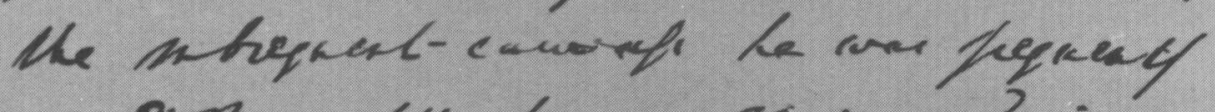
At DPB suretti bouser Offering cotrece and

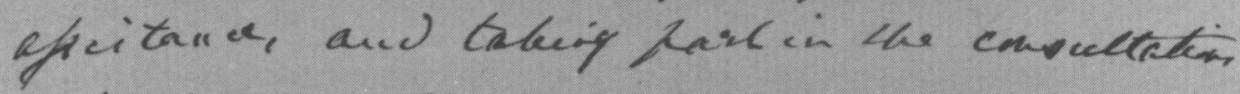
of hiffuinas. That be oficered llew ge Lejonk weo gacte basm. lefp, sunce te had tho chand of suceefe and merely vaited ta beteortis fnetien cin fork \&y the bos becetisis of fle toring testuma nials; and thater sook net rected Pifurfiat peaffre 6 thaed enask and ofer/ carreffed infacorer of Praseath-

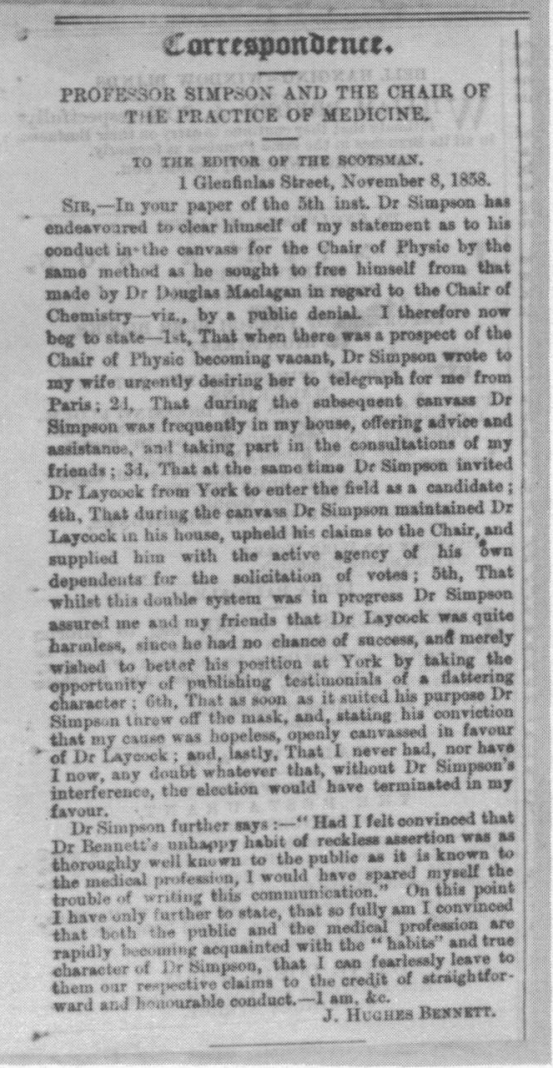

Figure 5: Page of the 'Account' including a press-cutting of John Hughes Bennett's letter to the Scotsman, 9 November 1858.

79

https://doi.org/10.1017/S0025727300071660 Published online by Cambridge University Press 


\section{Thomas Laycock}

reckless disregard for the truth was well known. On that occasion he called into his council Dr Alexander Wood, whose election to the chair he had so bitterly opposed. In nothing was Dr Simpson more remarkable than in a facility of making friends into enemies and treating enemies as friends. The subjoined is Dr Simpson's letter. ${ }^{48}$

This naturally called forth a rejoinder from Dr Bennett, in which he specifically charged Dr Simpson with acts of treachery. ${ }^{49} \mathrm{He}$ affirmed that Dr Simpson urgently pressed Mrs Bennett to telegraph her husband home from Paris; that during the subsequent canvass he was frequently at Dr Bennett's house, offering advice and assistance, and taking part in the consultations of his friends. That he assured them Dr Laycock was quite harmless, since he had no chance of success and merely wished to better his position in York by the publication of flattering testimonials, and that as soon as it suited Dr Simpson's purpose he threw off the mask and openly canvassed in favour of Dr Laycock.

Nor was it quite true that Dr Laycock at first encouraged the notion which Dr Bennett and others entertained, that he was a man of "no position in York" and had little chance of success in Edinburgh. And in conversation at Dr Simpson's it was remarked that the effort if it ended in failure would be beneficial to Dr Laycock, as it would certainly make his merits better known in England. With this view Dr Simpson advised a much wider circulation of Dr Laycock's testimonials in Yorkshire than was really given to them. The thing had too much appearance of charlatanism.

Dr Simpson in his reply, which was a very long one, with a good deal of general pleading and suppressio veri did not rebut the substance of Dr Bennett's statements as to the facts. He only endeavoured to explain them away. He acknowledged he was a party to the scheme of bringing Dr Sharpey into the University as "a matter of high importance to the interests of the University"; that if he upheld Dr Laycock's claims it was always done as "secondary to Dr Bennett's claims", whom he esteemed the best of the candidates; and that he was amongst the last, if not the very last of his friends to give up all hopes of his success. His letter is subjoined. ${ }^{50}$

Undoubtedly, Simpson took the credit to himself in private when the election was over, of having secured the chair to Dr Laycock although he faintly denied the "soft impeachment"; while all the circumstances detailed by Dr Bennett were looked upon by Dr Laycock and the public at large as proofs of his preference for Dr Laycock over the other candidates. It was not, indeed until the publication of these letters that Dr Laycock was at all informed as to the extent to which Dr Simpson was in the confidence of Dr Bennett and his friends. Dr Bennett was not slow to seize upon the weak points of Dr Simpson's letter in a reply and added thereto further statements as to the interference of $\mathrm{Dr}$ Simpson with Dr Bennett's friends. ${ }^{51}$

This correspondence elicited expressions of opinion from various quarters, Dr John Renton especially, who proposed Dr Laycock at the election was equally offended with the dogmatism of Dr Bennett and the subtle hints at Dr Laycock of Dr Simpson. He therefore wrote two letters; one published in the Caledonian Mercury of 22 November 1858 , in which he showed that Dr Laycock was preferred for his merits alone, and not as a

48 Press cutting, Daily Scotsman, 5 November $1858\{t\}$.

49 Press cutting, Daily Scotsman, 9 November $1858\{\mathrm{t}, \mathrm{p}\}$.

50) Press cutting, Daily Scotsman, 13 November 1858 [with annotations] $\{t\}$.

51 Press cutting, Daily Scotsman, 18 November 1858 [with annotations] $\{\mathrm{t}\}$. 


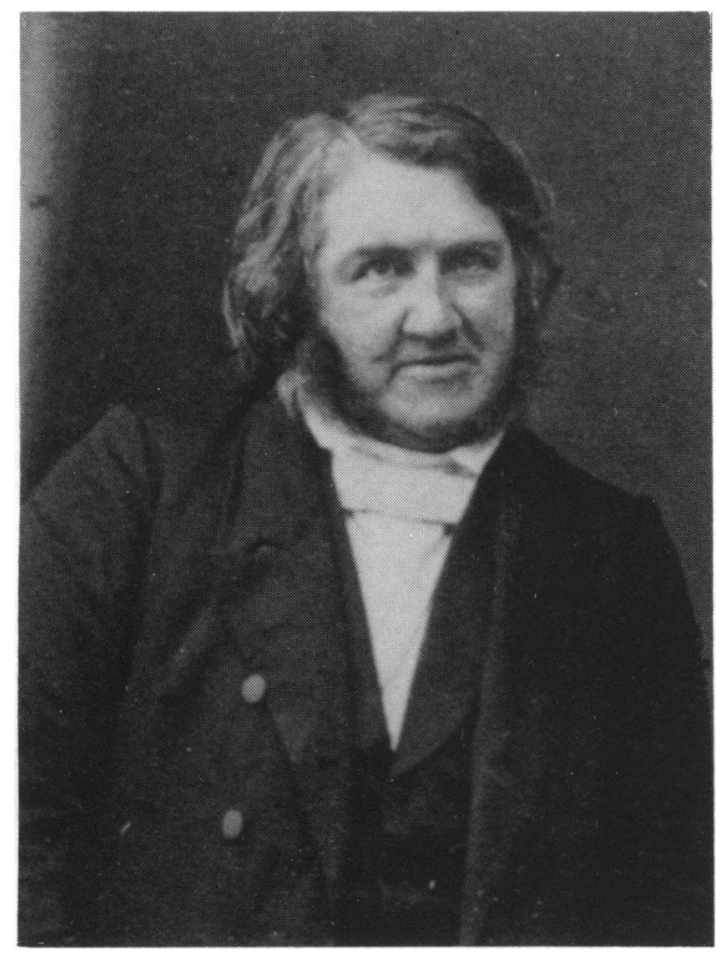

Plate I(a): James Young Simpson

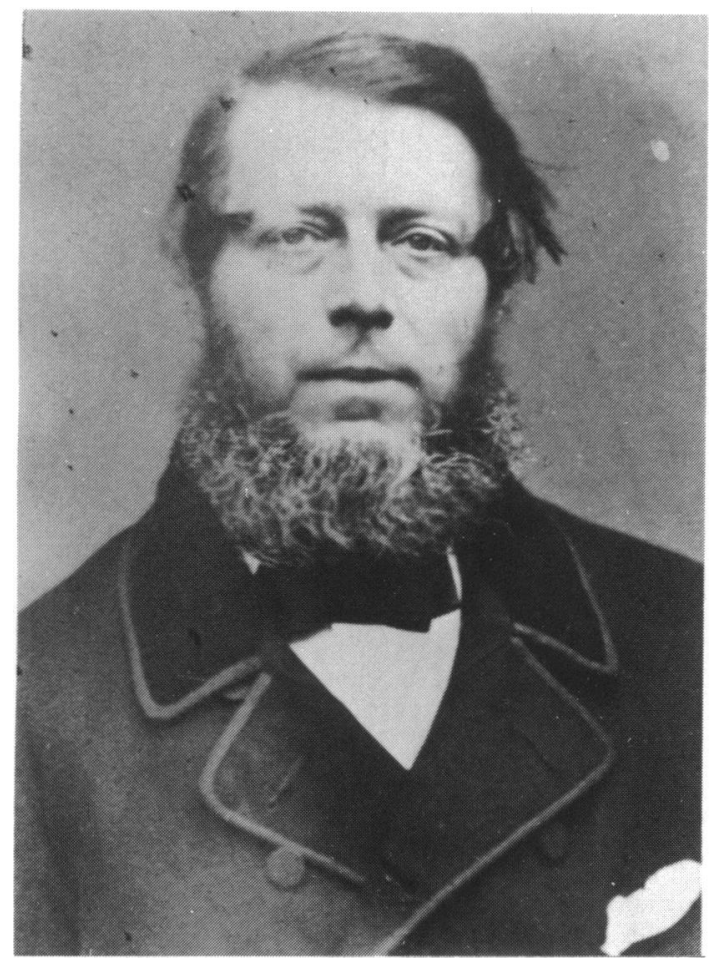

Plate I(c): John Hughes Bennett

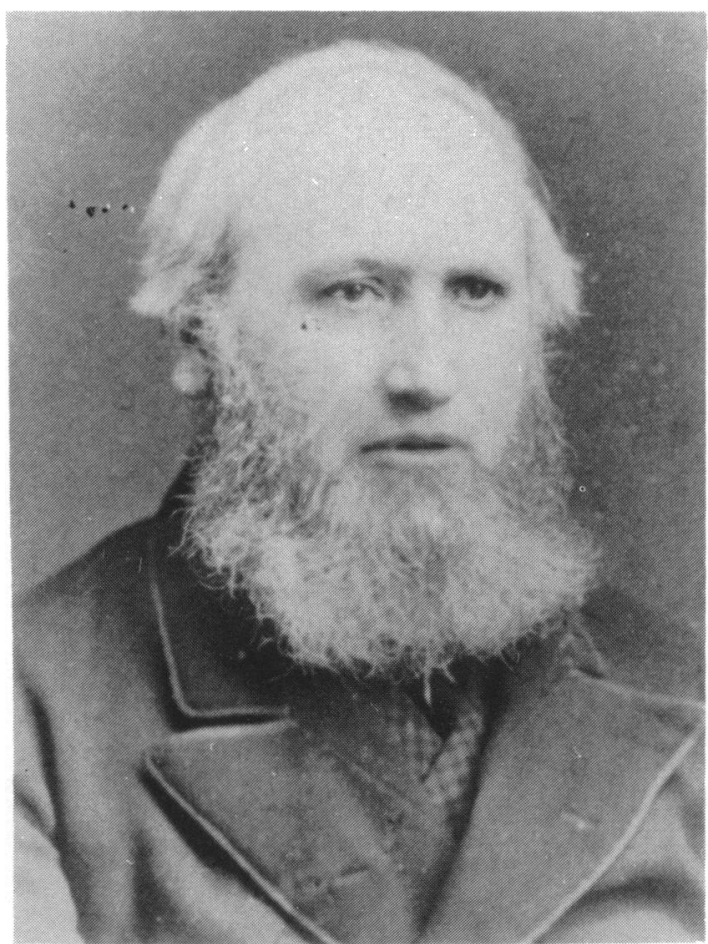

Plate 1(b): Alexander Wood

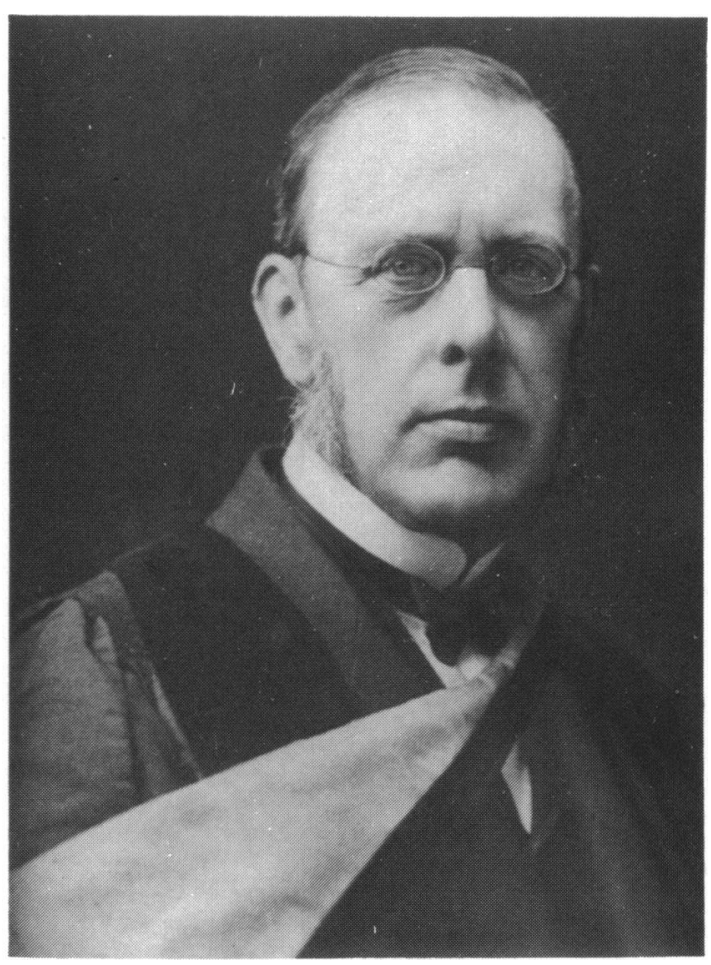

Plate $1(d)$ : William Tennant Gairdner 


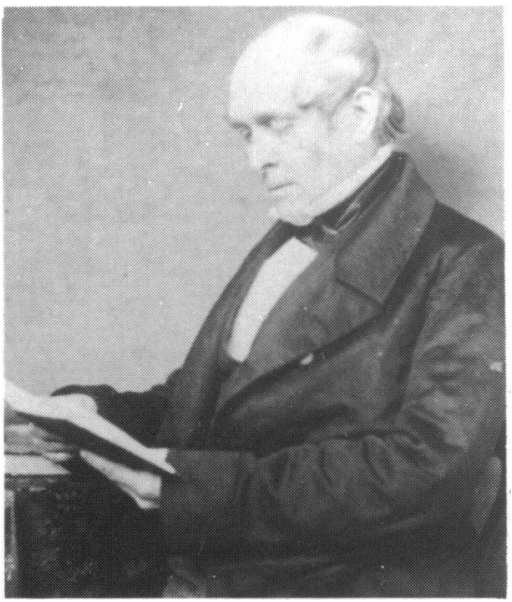

Plate 2(a): John Renton, Councillor

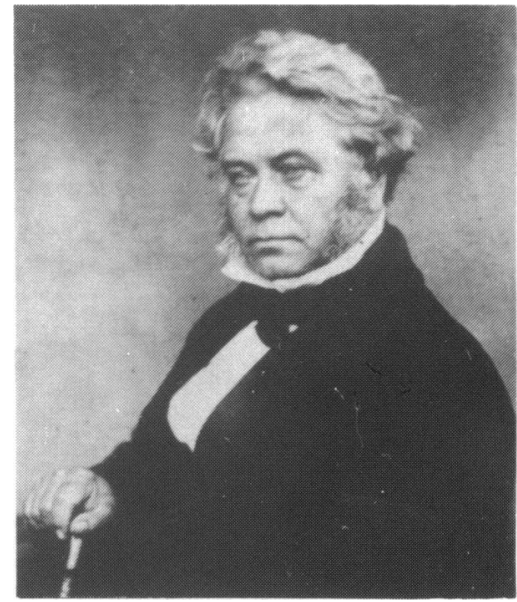

Plate 2(b): William Dick, Councillor

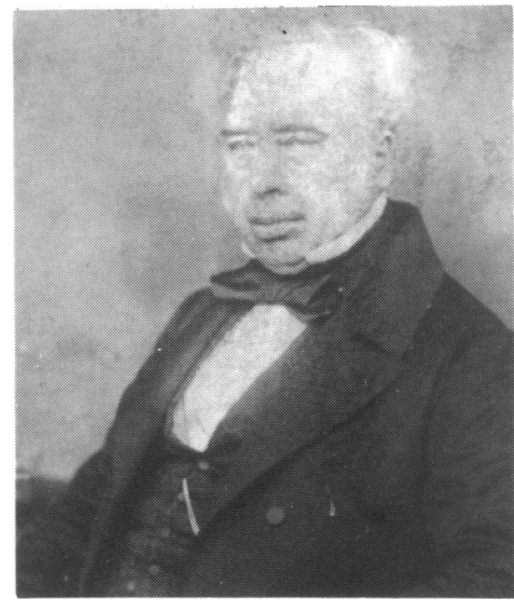

Plate 2(c): John Kay, Councillor

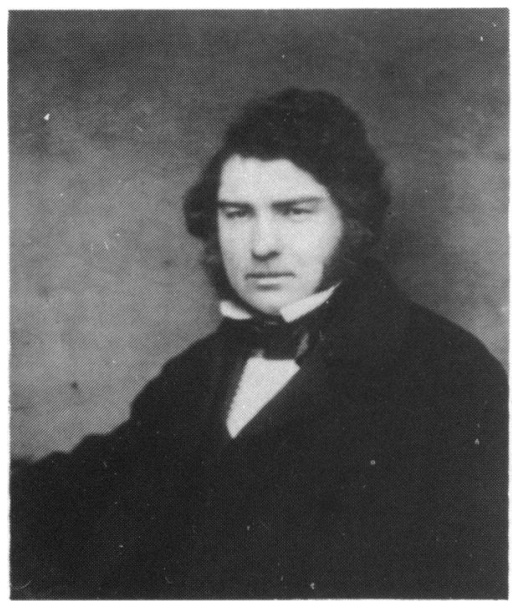

Plate 2(d): David Dickson, Councillor

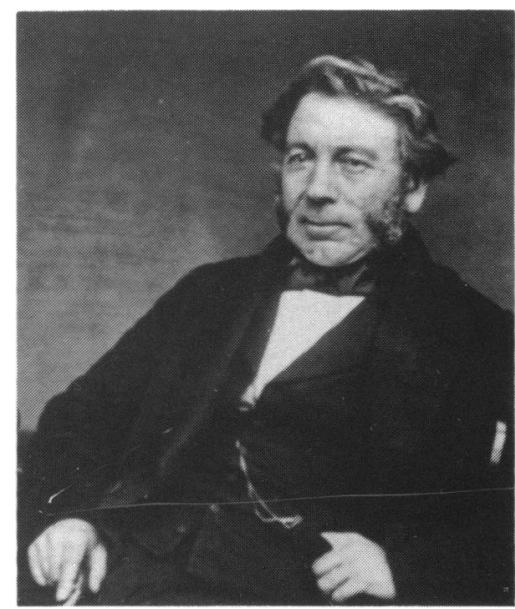

Plate 2(e): Francis Richardson, Councillor 


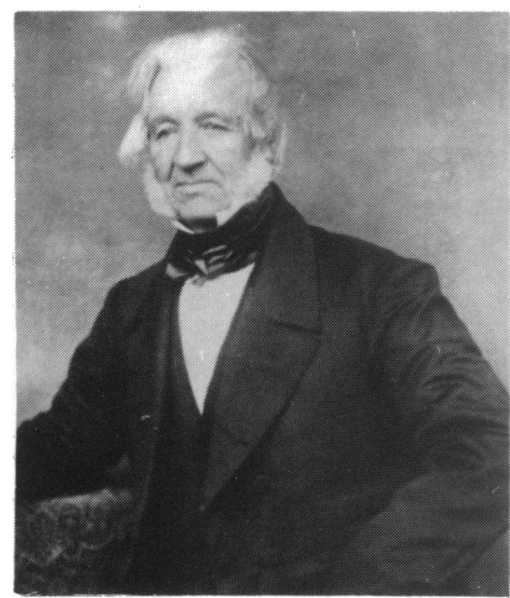

Plate 3(a): James Gray, Councillor

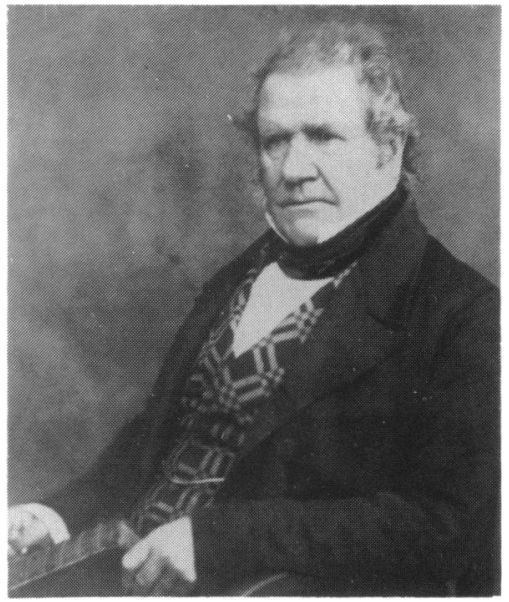

Plate 3(b)): Thomas Murray, Councillor

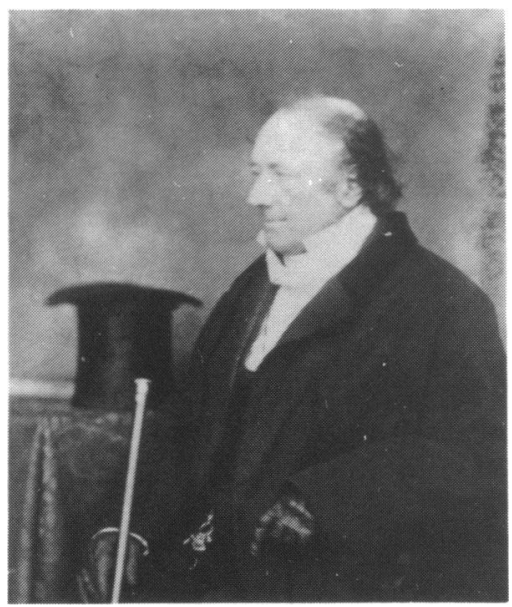

Plate 3(c): John Robertson Sibbald, Councillor

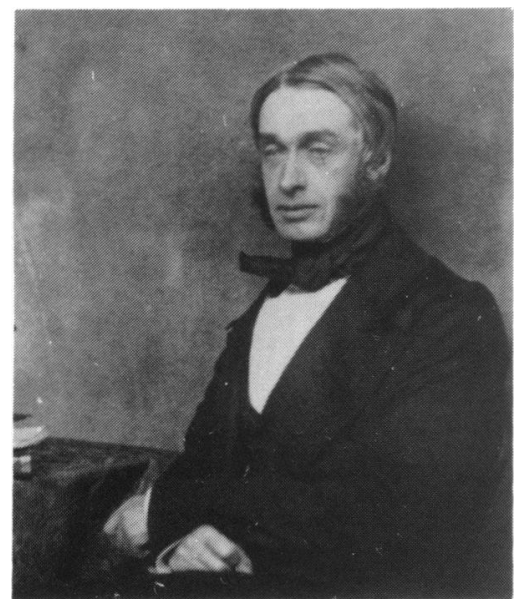

Plate 3(d): George Crichton, Councillor

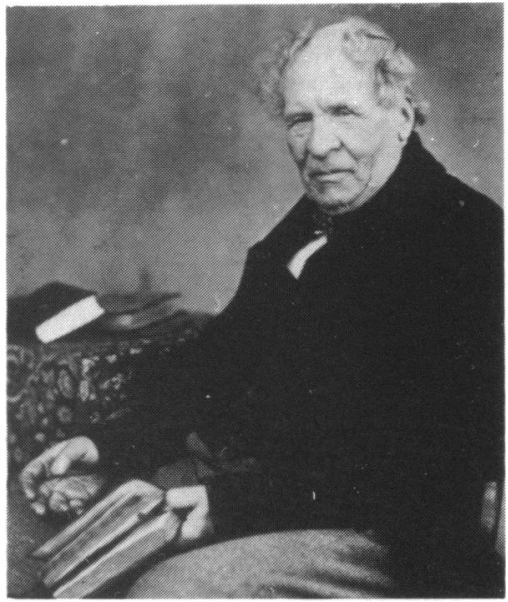

Plate 3(e): William Tullis, Councillor 


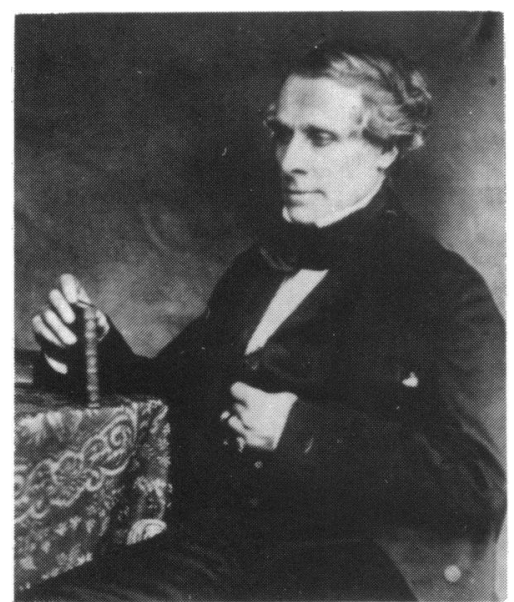

Plate 4(a): Alexander Hill, Councillor

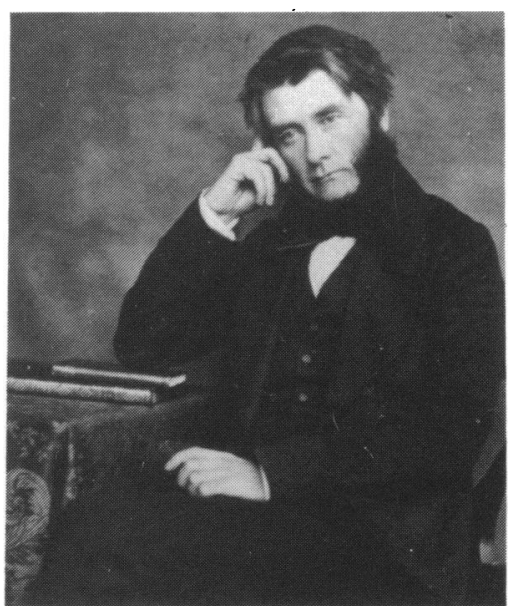

Plate 4(b): Robert Grieve, Councillor

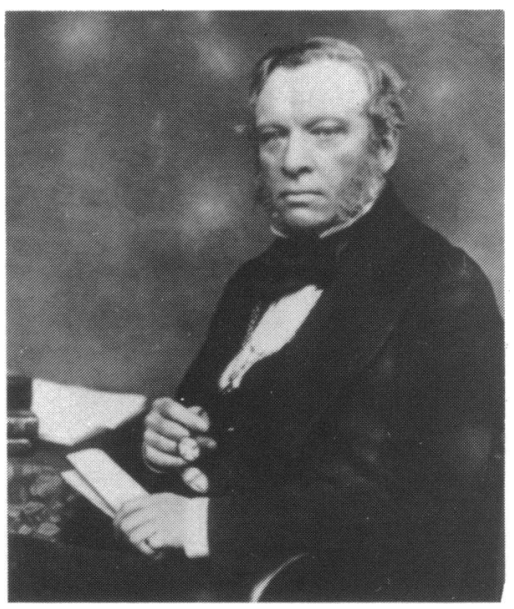

Plate 4(c): Adam Morrison, Councillor

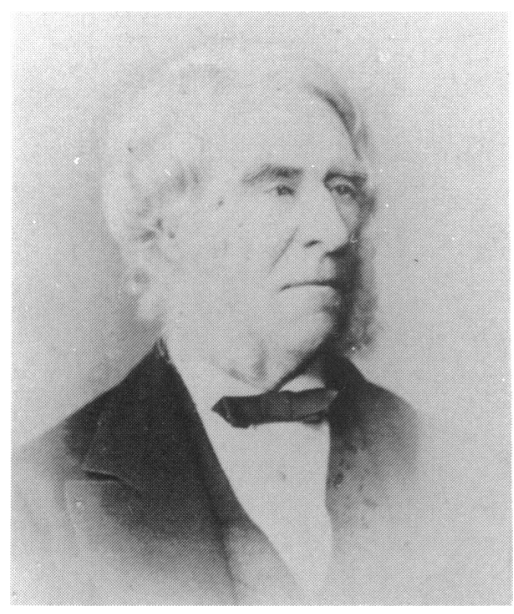

Plate 4(d): Robert Christison

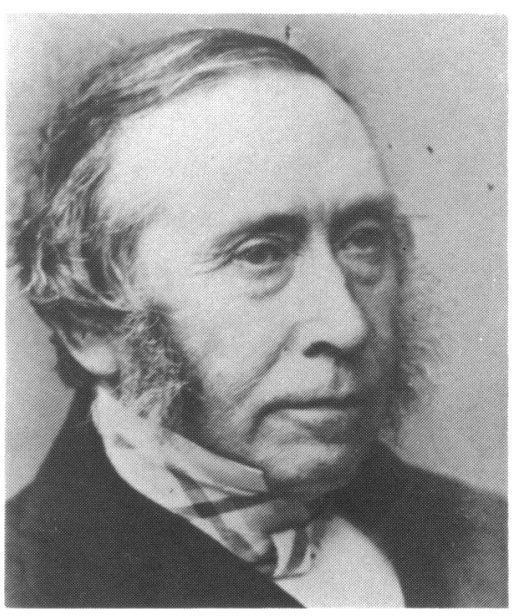

Plate 4(e): James Syme 


\section{Main Text}

pis aller to keep out Dr Wood. ${ }^{52}$ The other was addressed to Dr Simpson for publication (who however refused to publish it and never showed it to Dr Laycock) and set forth that Dr Simpson's influence was not felt in the election, which was decided on the merits of the candidates. Mr William Bell, a lawyer in Elder Street, and a supporter of Dr Wood wrote privately to Dr Laycock in the same sense. ${ }^{53}$ These letters are annexed as containing facts illustrative of the contest for the chair, and of the share persons took in it. Subjoined is Dr Renton's. 54

Dr Simpson probably acted from various motives accordingly as circumstances changed. When he first sent for Dr Laycock he did not probably think seriously of him as a candidate. He had perchance other motives. A year or two before, Dr Laycock had expressed to Dr Simpson his wish to give a short course of lectures on psychology in Edinburgh and Dr Simpson had communicated with the directors of the Philosophical Institution on the subject without success. Then, again, he had given Dr Laycock a strong testimonial when a candidate for the office of Physician to the York County Hospital in the previous autumn, and this had given offence from its peculiar phraseology to Dr Simpson, Mr Hey and Mr Husband, the other medical officers. Now the fact of Dr Laycock being thought fit to be a candidate for the Chair of the Practice of Physic in the University of Edinburgh would be a loud reply to the directors of the Edinburgh Philosophical Institution, and the Citizens of York, and others who had failed to appreciate Dr Laycock's merits. Then, again, Dr Simpson liked to place physicians and surgeons resident at a distance from him under obligations with a view to securing their interest in his favour for consultations and recommendations. This was part of his fixed policy and was no doubt carried out on the occasion of sending for Dr Laycock and offering him the hospitalities of his house.

But Dr Simpson was only vain and proud. In particular he wished to be thought a man of large influence over the public, and thus secure the subserviency of all those seeking place or position or patients. On no point was he weaker than on this. Hence, he would not only write to others from the same motives as those which influenced him in writing to Dr Laycock, but he would look sharply out to discover which was likely to be the winning candidate so he might be not only on the winning side, but so act as to impress the winner that success was due to his advice and exertions. Now at first, success was most probable with Dr Bennett; at all events the sleeping power on the side of Dr Laycock was wholly imperceptible. Dr Simpson therefore took in the first instance, the side of Sharpey, Syme, Bennett and the supporters of the University generally. But when he found that the snug arrangement of the professors not only for Alison's but for Bennett's chair was not likely to be popular, and that the strength of Dr Laycock's position was increasing day by day as his testimonials came before the public, he found it necessary to finesse between Drs Bennett and Laycock so that he might be on the winning side which ever was elected. In this way he was kept balancing between the two. But since his predilections for Dr Laycock were necessarily shown to those intimate with him, as Mr Carmichael, Dr Priestley and Mr Alexander R. Simpson \{b\}, a nephew and a medical student of the

\footnotetext{
52 Press cutting, Caledonian Mercury, 22 November $1858\{\mathrm{t}\}$.

53 Letter, W. S. Bell to T. Laycock, 9 November $1858\{t\}$.

54 Letter, J. Renton to J. Y. Simpson, 2 December 1858 [copy] $\{t\}$.
} 


\section{Thomas Laycock}

University resident in his house, while his labours for Dr Bennett were not known to them, these naturally worked for Dr Laycock in the belief that their services would not be forbidden-as they were not. While at the same time their efforts naturally attracted attention. $^{55}$

\section{(vi) The Final Struggle}

On occasions of an election by the Town Council of Edinburgh nothing decisive is known until a few days previously to the election. The jury must have the whole evidence before them before they can express an opinion as to the relative merits of the candidates, whatever decision they may already come to. And as a general rule they take care not to pledge themselves prematurely. As the day therefore draws near, the candidates and their friends redouble their efforts to influence the minds of the electors. Fresh sheets of testimonials are issued in succession, each if possible stronger than the last. At his departure from Edinburgh Dr Laycock had therefore another batch of testimonials ready for distribution headed by one from his Grace the Archbishop of York (Dr Meergraves), the Dean of York (Dr Cockburn) and the canons minor and residentiary, which was obtained by Dr Laycock's friend the Reverend E. S. Raines, Vicar Choral. He had hardly reached York, however before Dr Simpson wrote to him to announce that the final struggle had begun and he must return at once. ${ }^{56}$

On arriving at Edinburgh Dr Laycock found his prospects of success had generally improved, and that upon the whole he might consider himself the popular candidate. ${ }^{57}$ For although he had not a large number of avowed first votes, he clearly saw that the majority of the electors would be in his favour at a final vote between himself and any of the others.

Dr Laycock had hardly reached Edinburgh than he issued his fourth and last address to the Town Council together with another series of testimonials. ${ }^{58}$ These were from former pupils, from forty members of the York Institute; from Trousseau and Gendrin of Paris, and Virchow then of Wurtzburg, various Irish physicians, E[dwin]. Chadwick and various practitioners in London and the provinces, Sir John Forbes's testimonial was issued by itself just before the election.

The testimonial from the York City Council referred to in the Address was not printed by the advice of Dr Laycock's “Mentor", as he was designated at 52 Queen Street (see letter on last page) [n 56]. ${ }^{59}$ It was originally proposed to have an official address got up and agreed to at a meeting of the Council, but Mr Robert $\mathrm{H}$. Anderson objected on formal grounds. ${ }^{60}$ This person was a disreputable lawyer in York who was probably offended with Dr Laycock because on his marriage Dr Laycock had ceased to visit with him, not choosing to rank a man of his equivocal character amongst those to whom he introduced his wife. ${ }^{61}$ The formal objection could not be overcome, but it gave rise to a discussion in

\footnotetext{
55 Letter, R. Chambers to T. Laycock, 28 September $1855\{t\}$.

56 Letter, J. Y. Simpson to T. Laycock, 22 September $1855\{\mathrm{t}\}$.

57 Letter, T. Laycock to A. Laycock, 25 September $1855\{\mathrm{t}\}$.

58 T. Laycock, Fourth address, 25 September $1855\{t\}$.

59 Press cutting, Yorkshireman, 12 September 1855.

60 Press cutting, Yorkshireman, 15 September 1855.

61 Press cutting, York Courant, 15 July 1847.
} 


\section{Main Text}

Dr Laycock's favour which being published in the York papers ${ }^{62}$ enabled Dr Laycock to bring it before the Edinburgh Town Council together with editorial remarks of a complimentary character. ${ }^{63}$ A memorial was nevertheless signed by the members of the Council with one or two exceptions. ${ }^{64}$

The sanitary inquiries referred to in the debate were conducted by Dr Laycock as honorary secretary of a local Committee formed in York to cooperate with the Health of Towns Commission. He spared neither labour nor thought in the work, so that the result was a report which had a wide circulation both in the United Kingdom and the United States and which was considered the most complete of any given in to the Government Commission. Subsequently he founded in York a "Health of Towns" Association, and by this kept the public attention directed to the state of the sewage, the construction of lodging-houses, the establishment of baths and wash-houses, the drainage of the church yards and legislation for the prevention of the smoke nuisance in York and elsewhere. As to all these, except the establishment of baths and wash-houses, Dr Laycock was successful. These were delayed, mainly from financial considerations. Mr Hudson, the socalled "Railway King" when at the height of his prosperity and Lord Mayor of York attacked Dr Laycock's report in Parliament, questioning its accuracy as being the work of a "monomaniac" on the subject and charging the writer with interested motives.

Dr Laycock's essay on "Medical ethics", which was published in the British and Foreign Medico-Chirurgical Review for July 1848, had been already under the consideration of Dr Simpson and Mr Chambers as to the propriety of reprinting it. They considered it should be reprinted, but in the form in which it first appeared and circulated as if the copies had been got from the original types. Dr Laycock however decided to print it in the $12 \mathrm{mo}$. form with a dedication to his mother. This and the essay itself were much criticised, and it was thought to have been a failure as to its influence in the election. But Dr Laycock was informed by Dr Renton that it certainly secured the vote of Ex-Bailie Gray, a retired tradesman and warm religionist, and influenced others very favourably. It was published under the title Religio Medicorum: a Critical Essay on Medical Ethics. ${ }^{65}$

The tactics pursued by the different candidates varied much. Religious, political, academical and personal considerations deeply influenced these as to all the Edinburgh candidates. An attempt was made by Dr Bennett, and Dr Wood's friends to revive the scandal of Simpson's of York, and represent Dr Laycock as a quarrelsome individual but it signally failed. Dr Wood's friends made it well known that Dr W. T. Gairdner had left the Unitarian church only a few months before and sneered as the reason alleged namely, some pecuniary differences with the pastor, as if that was a reason for a change of faith. Nor did Dr Laycock's friends neglect this instrument of warfare although he disdained it; for Mr Carmichael helped to spread the story, while one morning when Dr Laycock called upon Bailie Kay, spirit merchant in Jamaica Street, he found Dr Macfarlane denouncing Dr Gairdner's Unitarianism in the bitterest terms.

62 Press cutting, Yorkshire Gazette, 15 September 1855.

63 Press cutting, York Herald, 15 September $1855\{t\}$.

64 Press cutting, unidentified Yorkshire newspaper, n.d. [c. 15 September 1855].

65 T. Laycock, dedication page of the Religio medicorum [c. September 1855] \{p\}. 
Thomas Laycock

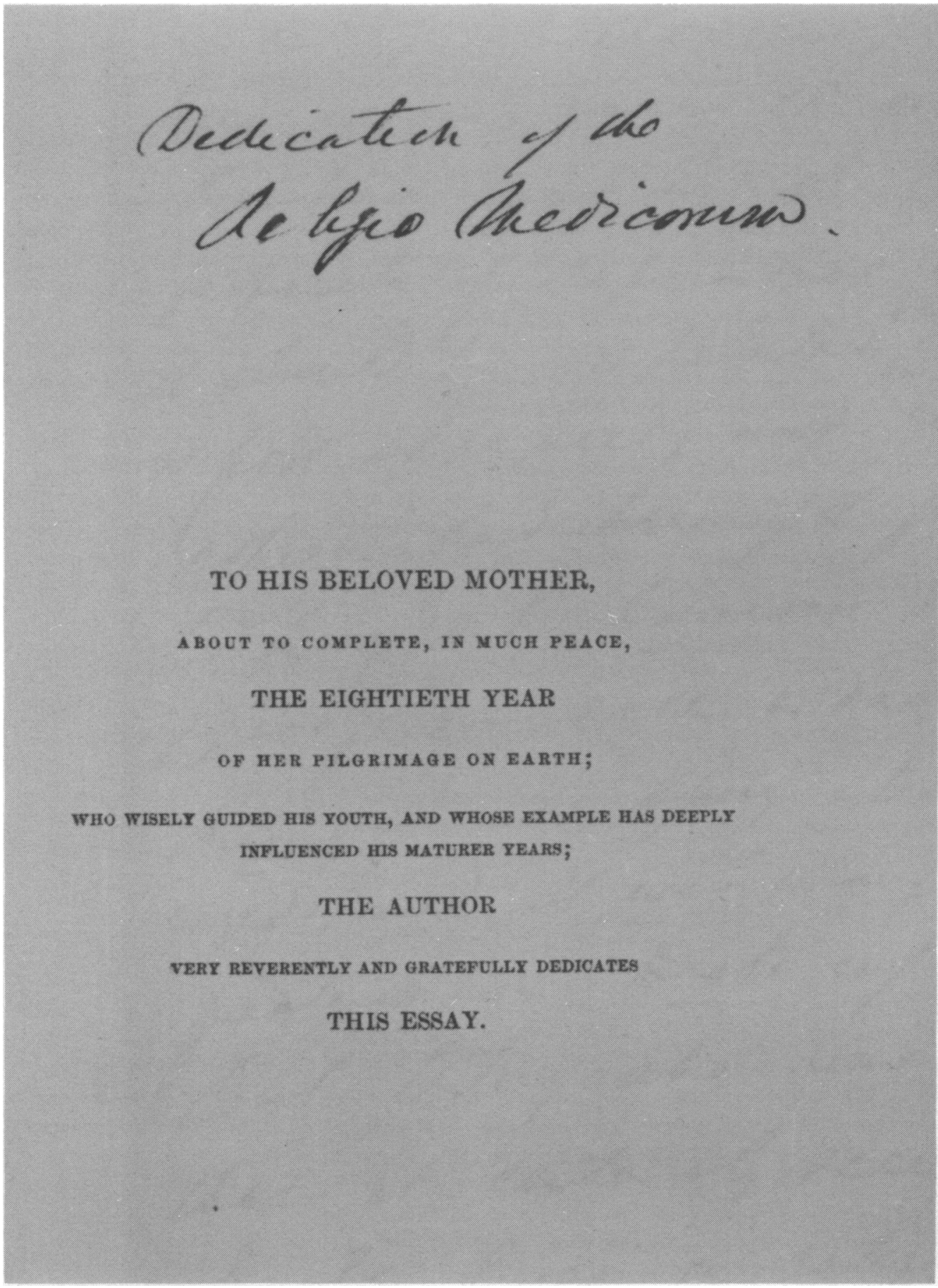

Figure 6: The dedication page of Religio medicorum. 


\section{Main Text}

The envenomed antagonism between Drs Bennett and Wood incited them to mutual disparagement, and as each saw his most dreaded opponent in his most hated rival they looked rather to what would damage each other than Dr Laycock of whom they thought little. It was not therefore until a few days before the election that Dr Bennett looked upon Dr Laycock as an antagonist at all worth notice, while Dr Wood was so confident of success to the last moment that he had ordered a splendid champagne lunch for the recreation of his committee and the celebration of his victory.

Under these circumstances Dr Laycock pursued his canvass. While travelling backwards and forwards between London [Edinburgh?] and York he had much time for reflection on the tactics of the campaign. He had succeeded remarkably well with the evidence of his fitness. The testimonials were such, as Sir James Clark had well observed, that any man might be proud of (see letter of 26 September) [n 15] and which could warrant the active support of his friends against the other candidates, if merit only was to be considered. But it was obvious that according to the method of voting adopted, and as described by Dr Bennett in his letter [n 51], the contest would finally end in a dual between two, in which the friends of the three other candidates would have the casting votes. Dr Laycock, therefore while seeking first votes on the strength of his testimonials, laboured quietly but diligently from the very first to secure the support of the other candidates and their friends. Having met them at dinner at Dr Simpson's this was not difficult as to Douglas and Gairdner the two junior candidates who from the first were well-disposed to Dr Laycock. He then secured four out of five of Dr Gairdner's friends. Dr Douglas's personal recommendation was secured, but his cousin went finally with the Free Church, having the Provostship at the next vacancy in his eye (and which he attained).

In canvassing the councillors, Dr Laycock spoke in the highest terms of the merits of the different candidates and this had a good effect, for it predisposed the candidates themselves to be friendly while it contrasted favourably as to candour and gentlemanly conduct with that of Dr Wood and Dr Bennett. He did not even ask for a vote in the first instance, but assuming that the electors would (as they said they would) be influenced as jury men by the evidence, he claimed the privilege of being his own advocate before the jury, alleging as a reason for his taking the liberty of speaking so much of himself, as rather of the merits and position of the gentlemen who had given the testimonials in his favour, that being a stranger in Edinburgh and unknown to a single member of the Council he had in fact no one to advocate his cause, while the others had friends of life-long standing, colleagues and native committees at their back. He therefore begged leave to press upon the electors a very careful consideration of the evidence laid before them, and especially the need of inquiring into the position and character of the testifiers.

As the time drew near, each day led to an expression of intentions on the part of one or another of the councillors. ${ }^{66}$ So that by Wednesday, 26 September Dr Laycock had learnt that he was sure of seven votes, while Bennett had only eight and Gairdner four; the others not so many. For Dr Laycock were J. Clark, Bailie Kay, William Forrester, Dr Renton, Francis Richardson, Ex-Bailie Gray and D. Dickson. J. Clark, however, that same evening wrote a very characteristic letter to Dr Laycock withdrawing his promise. He was a

${ }^{66}$ A list of the Town Council of Edinburgh, 1855 [with annotations] $\{t, p\}$. 


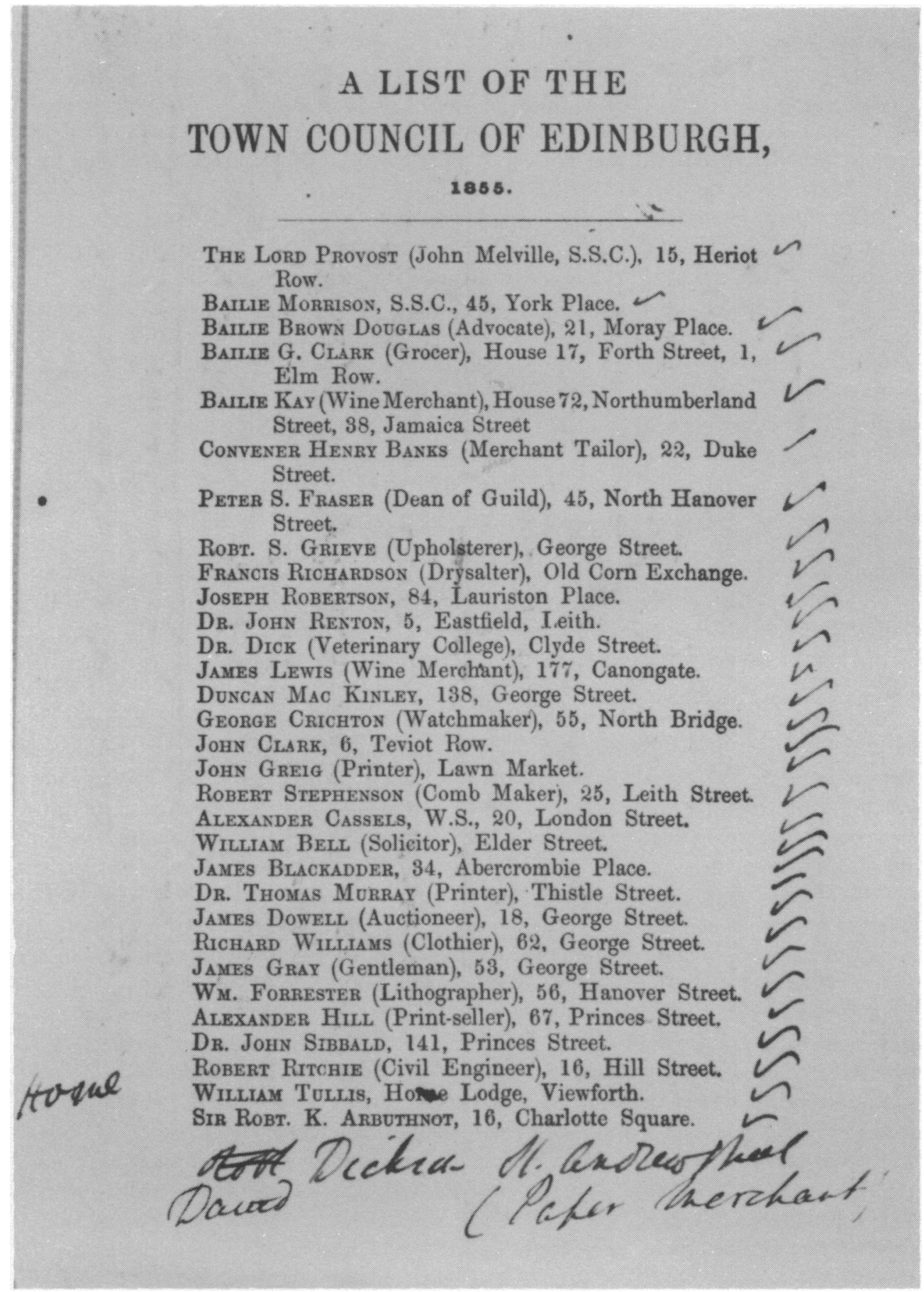

Figure 7: The printed list of the Town Council of Edinburgh, 1855. 
"cannie" Scotchman, bigoted, meaning well but easily influenced. His no meaning in his letter is worthy of a Machiavelli. ${ }^{67}$ Dr Gairdner had P. S. Fraser, Cassels W.S., Dick and Lewis and probably Bailie Clark. Each evening a list was made out of the state of opinion amongst the councillors, of which the annexed is an example, being the first. ${ }^{68}$

On 28 September Dr Laycock met Dr Gairdner in the street and showed him his list of supporters. Dr Gairdner frankly acknowledged that he had not so many nor so influential. Dr Laycock frequently saw Mr Fraser, a friend and supporter of Dr Gairdner's in the first instance, but of Dr Laycock's in case Dr Gairdner withdrew. Mr Fraser was a cousin of Mrs Robert Chambers, and an intimate friend of Mr D. Hay, who both influenced him strongly in favour of Dr Laycock's claims. Mrs R. Chambers was a warm supporter of Dr Laycock and a fortnight previously had already settled in her own mind that Dr Laycock was to be elected. Mr Fraser took an early opportunity of seeing Dr Gairdner and suggesting to him the propriety of withdrawing in favour of Dr Laycock, as Dr Laycock had convinced him he was the stronger of the two, and to this Dr Gairdner assented.

On Saturday, 29 September (preceding the Tuesday of the election) the councillors who had not declared themselves were visited by Dr Laycock to hear definitely from them the conclusion at which they had arrived. ${ }^{69}$ When they mentioned Dr Wood and Dr Bennett, Dr Laycock expressed his gratification at the excellent choice they had made, and added a hope that he might have the honour and pleasure of their second vote. In this way he secured eight out of Dr Wood's twelve pledged votes. ${ }^{70}$

Amongst the councillors who were most active in Dr Laycock's favour was Dr Renton. He has already been referred to as a friend of Lizars. He was in practice at Pennicuick and more particularly under the patronage of Sir George Clerk. This latter gentleman was a Tory, while Dr Renton was a Whig. When, therefore, the Reform Bill became a subject of agitation Dr Renton took the Whig side and supported the reform measures and agitated very actively to the great annoyance of his friend and neighbour, the baronet. The result was that he had to leave Pennicuick, but the people presented him with a handsome testimonial in the shape of a time-piece, silver salver, and silver punch-bowl. He had considerable influence over Professor Dick of the Veterinary College in Clyde Street and, as one of the two medical members of the Council, his opinion was doubtless of some weight with the others. ${ }^{71}$

Professor Dick could not be brought to declare himself, but it was believed he was very favourably inclined to Dr Laycock. He had founded the Veterinary School, was a selftaught man, a bachelor, with a respected large family; hating the clergy because (as it was alleged) one of them had jilted his maiden sister who lived with him. He wrote to veterinary surgeons in York (Mr Day) and elsewhere to inquire into Dr Laycock's reputation and finally supported him in preference to Bennett. ${ }^{72}$

Bailie Kay, a wine-merchant, was, like Dick, a self-taught man. But he had not Dick's coarse nature and harsh tongue. On the contrary, there was much of the gentleman in his character. He told Dr Laycock that he had occupied a whole night in bed in reading and comparing the testimonials of the various candidates and could only come to the

${ }^{67}$ Letter, J. Clark to T. Laycock, 29 September $1855\{\mathrm{t}\}$.

68 Lists (2) of councillors' voting intentions, 25 and 24 September 1855 \{t, p\}.

69 Letter, T. Laycock to A. Laycock, 29 September $1855\{\mathrm{t}, \mathrm{p}\}$.

70 Letter, T. Laycock to A. Laycock, 30 September $1855\{t, p\}$.

71 Photograph of J. Renton $\{\mathrm{p}\}$.

72 Photograph of W. Dick $\{p\}$. 
Thomas Laycock

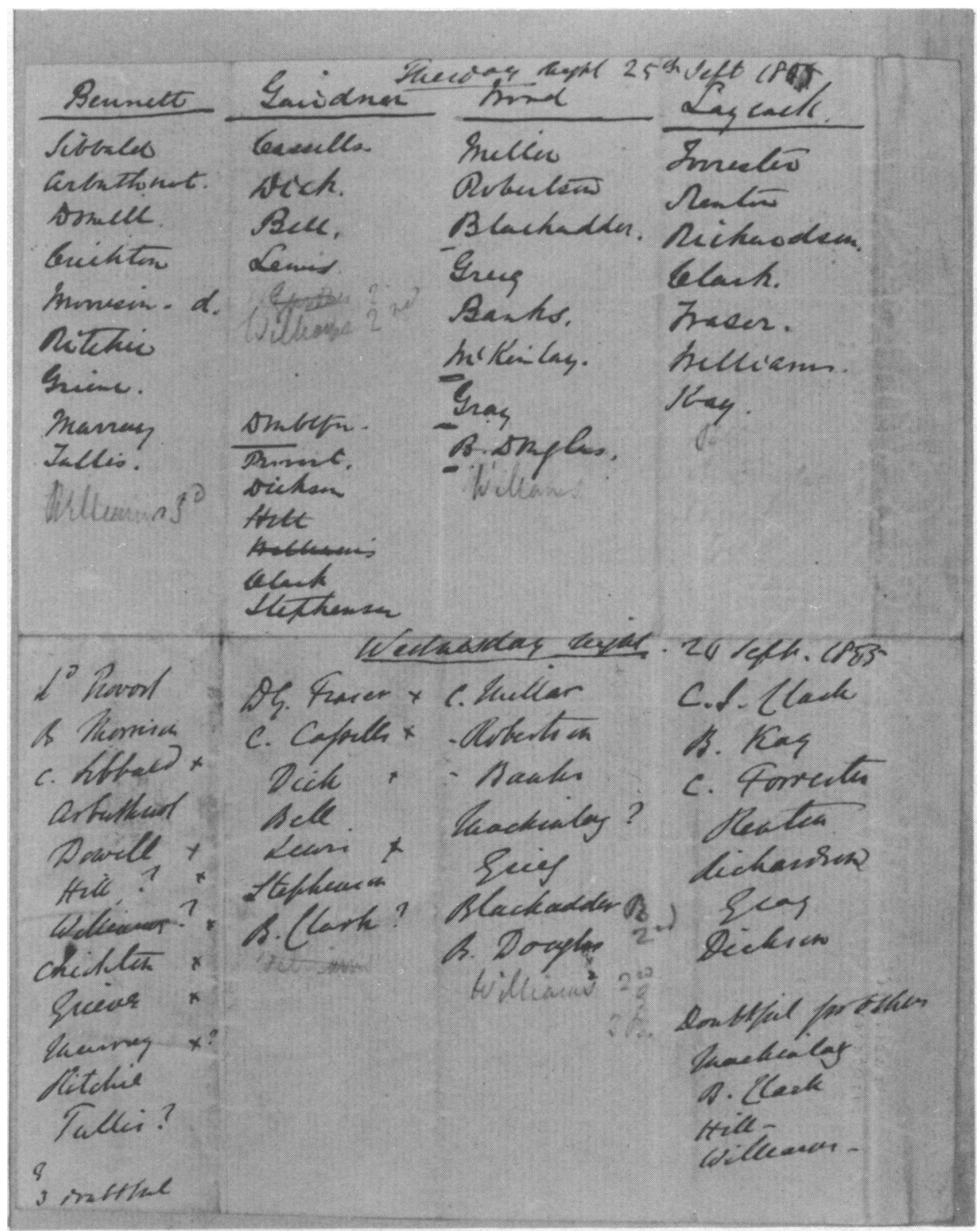

Figure 8: Lists of Councillors' voting intentions, 25 and 24 September 1855. 
conclusion that Dr Laycock's was the most satisfactory. He also said that Dr Alexander Wood had pressed him greatly, and had even beseeched him with tears in his eyes to vote for him. ${ }^{73}$

Bailie Clark, grocer in Elm Row was another of "Nature's gentlemen" whom Dr Laycock encountered in the Edinburgh Town Council. After a careful consideration of the evidence he decided to support Dr Laycock in the first instance and no importunity could make him swerve from his decision. He lamented to Dr Laycock how low the tone of feeling must be in those who ought to have known better, who pressed him to change his mind for sordid reasons.

Treasurer Dickson a paper merchant or wholesale stationer in Edinburgh was a Freechurchman and leaned somewhat to Dr Alexander Wood, in the first instance. He was a man of gentlemanly feelings, however, and sterling integrity and after further consideration of the testimonials given by the candidates, he became more and more convinced that Dr Laycock's were the weightiest. He wished, however, to have further testimony from the Lloyds in Yorkshire, and believing these were the Lloyds of Stockton on the Forest near York, Dr Laycock wrote to Mr George Lloyd and his sister Miss Lloyd of Peargreen[?] House, York. It was however the Lloyds near Thirsk who encouraged homeopathy. Their testimony being satisfactory, Mr Dickson finally declared for Dr Laycock and being a "Gold-Chain" in virtue of his office seconded Dr Renton at the election when he proposed Dr Laycock. ${ }^{74}$

Mr Francis Richardson declared warmly in favour of Dr Laycock. He was an Episcopalian and had a son in the church. Hence religious feelings probably confirmed him in the judgement he had formed of Dr Laycock's superior fitness. But there was no prominency given to any feelings of this kind. The Archbishop of York had written to Bishop Teviot of Edinburgh in Dr Laycock's favour, but to what extent that recommendation was influential Dr Laycock never heard. Mr Richardson told Dr Laycock that one of the candidates (or a friend of one) had sneered at Dr Laycock's German degree to him, but that seemed only to make him the warmer friend, for he answered "They had little to object to Dr Laycock when that was the strongest objection!"75

Ex-Bailie Gray was a retired butcher. He had been a fast liver in early life and was a man of warm feelings and strong passions. He was a Dissenter, and a teetotaller. Impressed by the superior weight of Dr Laycock's evidence in favour of his pretensions, he also leaned to him because Dr Laycock's father had been a Wesleyan minister and because in the dedication of his Religio Medicorum he had shown so much pious reverence towards his mother. He espoused Dr Laycock's cause very warmly and firmly resisted all efforts that were made to turn him in favour of the other candidates. ${ }^{76}$

Mr Alexander Cassels W.S. was at first a supporter of Dr W. T. Gairdner's. When that gentleman withdrew he finally declared for Dr Laycock and Dr Wood. He firmly resisted all importunities to change as to either of these in favour of Dr Bennett. Although $\mathrm{Mr}$ Fraser was an early supporter of Dr Laycock, he did not decide as to his second vote until Dr Bennett finding he had promised his first to Dr Laycock used insulting language to him

${ }^{73}$ Photograph of J. Kay $\{p\}$.

${ }_{75}$ Photograph of D. Dickson $\{p\}$.

${ }_{76}$ Photograph of F. Richardson $\{p\}$.

${ }^{76}$ Photograph of J. Gray $\{\mathrm{p}\}$. 
Thomas Laycock

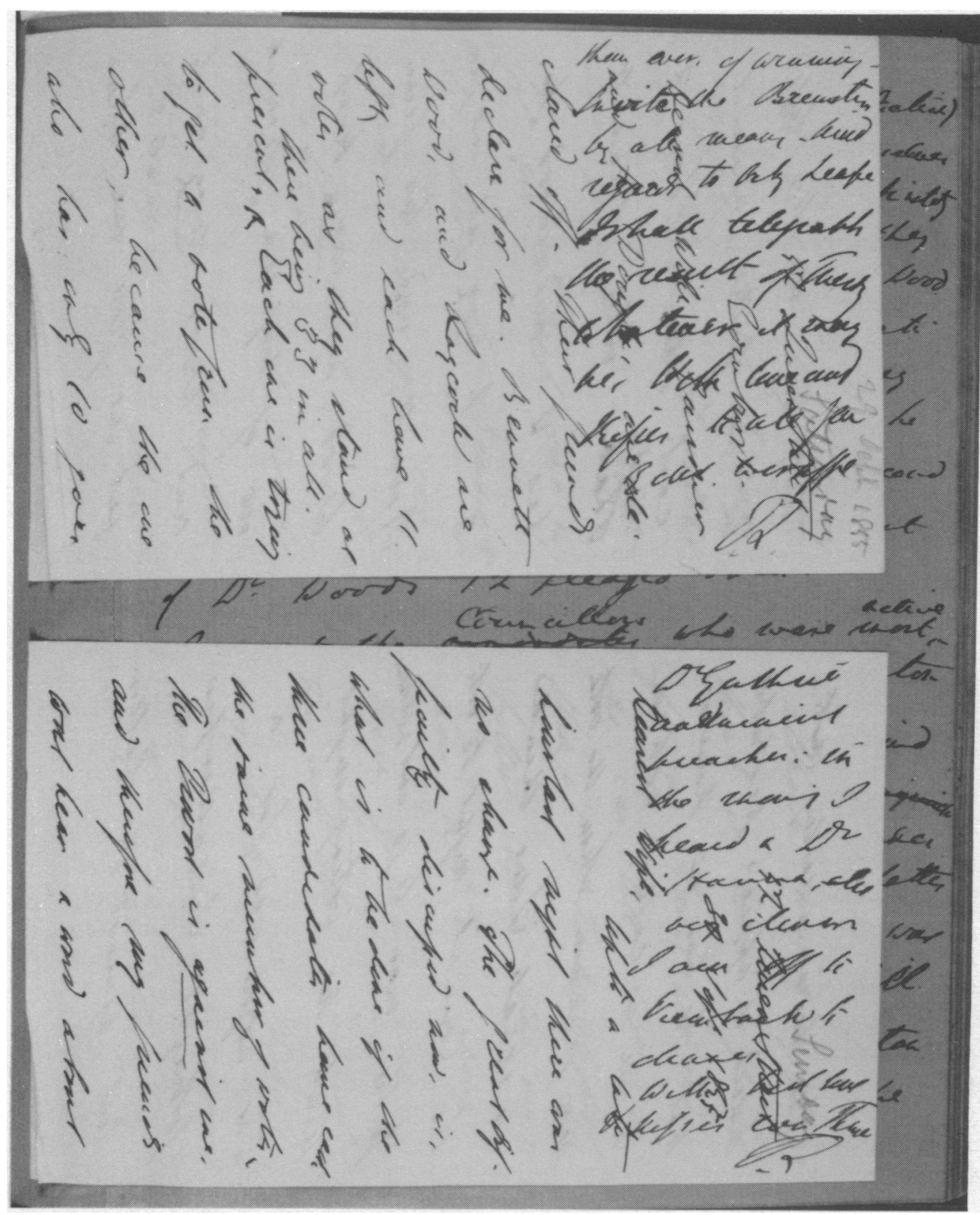

Figure 9: Two letters from Laycock to his wife showing the Main Text below. 


\section{Main Text}

and insisted that he had a "right" to the Chair of Physic in virtue of his occupancy of the Chair of the Institutes. He used the same language to the City Treasurer (Mr Dickson) when he found that his vote also was given to Dr Laycock. Mr Dickson had applied to Dr Simpson for his opinion as to the comparative merits of Drs Bennett and Laycock, but it was so qualified and so equally balanced between the two as to leave the inquirer in doubt-Dr Bennett's uncourteous conduct turned the scale against him. It was to this that Dr Simpson referred in his letter of 12 November 1858 when he speaks of the blasting effects of Dr Bennett's "temper and tongue" [n 50]. Both these gentlemen were at the same time thus determined in favour of Dr Wood as their second candidate in preference to Dr Bennett and as the second votes between these gentlemen finally determined which should be thrown out at the first voting, this circumstance was of great importance to $\mathrm{Dr}$ Laycock's final success.

There were two Englishmen in the Council, Stephenson and Williams. The first was favourably inclined to Dr Laycock at an early period, but for reasons best known to himself finally supported $\mathrm{Dr}$ Wood. Mr Williams was a London tailor and loudly proclaimed the Scottish doctrine of Scottish appointments for Scotsmen. This was curious in an Englishman, and was no doubt dictated by a feeling of interested subserviency to the Scottish prejudices. Mr Fraser called with Dr Laycock upon him and heard him say that he should give the preference to Gairdner and Bennett as against Dr Laycock. Mr James Ballantyne printer and glass-stainer and author of some pretty Scotch lyrics was an intensely patriotic Scotsman in the same sense as Mr Williams, and took an active part against the Englishman. He was an intimate friend of Mr D. R. Hay and Mr Fraser and therefore Dr Laycock got an introduction from these. Calling upon $\mathrm{Mr}$ Ballantyne with $\mathrm{Mr}$ Fraser, Dr Laycock related the particulars of his interview with the English tailor, and by way of meeting his Scottish prejudices assured him that he (Dr Laycock) would if elected probably be like Mr Williams, Hibernior ipsis Hibernis, for he alone of all the councillors had avowed prejudices of country as a motive for his decision. Duncan MacKinley led Dr Laycock to anticipate his support; when, however, he was pressed to give effect to his kind wishes, he declined to pledge himself and finally supported Dr Wood. He, however, freely gave Dr Laycock his second vote.

On Sunday 30 September the interest in the election did not abate. It now appeared however more clearly in what peril Dr Bennett's success was placed, although hitherto believed to be certain; the number of votes being manifestly in favour of Dr Wood against Dr Bennett at the second voting. In proportion as Dr Bennett's chances diminished, Dr Wood's increased and therewith his confidence. Indeed, he now was sure of success as according to the state of parties. Dr Laycock having only ten votes to Dr Wood's twelve and Dr Bennett's eleven, must necessarily be thrown out at the first voting, and then Dr Wood would beat Dr Bennett. There was however strong opposition to Dr Wood as the nominee of the Free-Church, just as there was to Dr Bennett as the nominee of Professors Syme and Christison. Dr James Simson had a special dislike to Dr Alexander Wood. He had circulated or at least repeated a scandal that Dr Wood had illicit intercourse with some woman who had borne a child to him. Whether the fact was correctly stated or not he had to apologise and pay $£ 50$ expenses of the proceedings already commenced against him by Dr Wood. Dr James Simson was a high Tory established churchman. Personally he was not liked; his eye had a greedy, monkey-like expression; his whole talk was of money and 


\section{Thomas Laycock}

his intellect and acquirements below par. Dr James Simson, a medical neighbour of Dr Bennett's, was one of the leaders in this sectarian feeling; he therefore on Sunday communicated with Dr Simpson as to the practicality of Dr Bennett's and Dr Laycock's friends coalescing in opposition to Dr Wood, knowing Dr Simpson's personal dislike to the latter. But this coalition could only be in favour of Dr Laycock, who now had such a probable majority of second votes, as to beat easily either of the candidates if not thrown out at the first voting - namely Dr Wood by eighteen to fifteen and Dr Bennett by nineteen to fourteen. This communication between Dr Simson and Dr J. Y. Simpson was kept secret by the latter from Dr Laycock to whom the circumstance first became known by the correspondence in The Scotsman newspaper. Dr J.Y. Simpson refused to concur in the step, (as he affirmed in his letter) [n 50] because he did not think Dr Bennett's case hopeless; and he relied in fact upon Mr Cassels and Ex-Bailie Gray giving their second votes to Dr Bennett, in which case he would have beat Dr Wood by a majority of one. He certainly canvassed Mr Gray for his vote for Dr Bennett and quarrelled with him after the election on the ground that he (Gray) had broken his promise to him (Dr Simpson) in promising his second vote for Dr Wood. Dr Laycock had to exert himself to reconcile the quarrel as it distressed his friend Mr Gray.

A circumstance worthy of notice recurred to Dr Laycock on this Sunday, when taken in connexion with the proposal of Dr Simson's, or "Long Simson" as he was nick-named. Dr Laycock had been disinherited by his uncle Robert Cattle, about fifteen years previously, and on the occasion which had led to it, his mother ( $R$. Cattle's sister) had recommended him to take comfort from the perusal of the Thirty-Seventh Psalm. He arose on Sunday morning, 30 September earlier than his host Dr Simpson, and was reading the Psalm when the latter entered the breakfast room. This gave occasion to Dr Laycock to relate the story of his disinheriting, at the conclusion of which Dr Simpson remarked "Well! you have me instead of your uncle". At church that afternoon (which Dr Laycock attended with Dr Simpson) Dr Guthrie gave out for the Psalm that portion of the metrical version of the Thirty-Seventh applicable to Dr Laycock's quarrel with his uncle, and then preached from the same verses. Dr Simpson professed to be much struck by the coincidence and looked significantly at Dr Laycock during the two coinciding points of the service, i.e. when the Psalm was given out and the text announced. Was this a coincidence? Or had Dr Guthrie selected the verses at Dr Simpson's suggestion? Be this as it may, Dr Laycock adopted the coincidence as a good omen for his success, and took care to mention it next day to his friends.

During Monday, 1 October (the day previous to the election) strong efforts were made by the various parties to modify the first and second votes, or declare themselves more definitely; for some still held back from a promise or even an expression of their intentions. Amongst these was Dr Murray of the firm of Murray and Gibb, who was originally a literary man. ${ }^{77} \mathrm{He}$ had printed the Edinburgh Medical Journal when under the management of the professors and was therefore intimately connected with Dr Bennett, who was for a time its proprietor. But he was opposed to the Free Church and clericomedical party and therefore was not likely to support Dr Wood. He affirmed constantly that Dr Laycock was emphatically both a scholar and a gentleman and was already ready

77 Photograph of T. Murray $\{p\}$. 


\section{Main Text}

to show himself well disposed to Dr Laycock. It was not therefore surprising that when canvassed by Dr Laycock, under all the circumstances he should clearly see that the probabilities were in Dr Laycock's favour and that he would have to support him by his second vote as against Wood. Dr Murray was a man of superior principles and attainments although a good example of the cautious calculating Scotchman. ${ }^{78}$

Another of Dr Bennett's supporters of the same class as Dr Murray, was Dr Sibbald \{b\}. ${ }^{79} \mathrm{He}$ was a general practitioner and had taken an active part in public matters for some time. He was of great service when the cholera prevailed in Edinburgh. Amongst his professional brethren his character was not in high esteem, but whether from prejudice or from his conduct did not appear. Mr George Crichton watchmaker was one of "Nature's gentlemen"-mild in temper, unassuming in manners, his sole object was evidently to secure a man for the chair best fitted in all respects for it, whether as to acquirements, practical knowledge, or moral character ${ }^{80}$ Although a first supporter of Dr Bennett he was strongly in favour of Dr Laycock's claims, as compared with the other candidates.

Ex-Bailie Tullis was another of Dr Laycock's supporters, respecting whom there was great uncertainty to the last. ${ }^{81} \mathrm{He}$ was a retired baker, his wife was an Episcopalian, and he not infrequently accompanied her to service at St John's. Dr Laycock noted this circumstance and engaged Mrs Tullis on his side against the constant pressure upon $\mathrm{Mr}$ Tullis in favour of other candidates. He was usually the last in the roll, or nearly so, and consequently when voting was nearly equal, his vote came with much of the weight of a casting-vote. Hence his frequent boast that it was he who got this professor or the other his chair. He was a very peculiar man, speaking with a strong Aberdonian accent. An amusing race to his house took place between Dr Simson in favour of Dr Bennett and Dr Macfarlane in favour of Dr Laycock. "Long Simson" beat [him] to the house door, but Dr Macfarlane got to the garden gate at the same time and called out to Tullis "I've a better man for you than he has!" Dr Macfarlane was then eighty years of age!

On Monday evening there was a meeting of Dr Laycock's friends at the Café Royal, namely Dickson, Renton, Gray, Bryson and another, with a view to arrange for the election on the next day. The lists were carefully gone over for the election and it was found that unless a vote could be obtained from Dr Bennett or Tullis secured, Dr Laycock would be rejected at the first voting; but if he could secure success at the first voting, he would be sure of his election at the second. ${ }^{82}$ It was obvious that he had a strong majority in his favour as against both candidates; while Dr Bennett had not a majority against either. It was obviously therefore the duty of Dr Bennett to retire but this he positively refused to do, although his friends did strongly solicit him to free them from their promises. It was under these circumstances that Mr Gray declared he would give his second vote to Wood.

After a careful consideration of all the votes the annexed statement seemed to be the probable result of the voting on the morrow. ${ }^{83}$ And on returning from the meeting between eleven and twelve o'clock Dr Laycock showed it to Dr Simpson. He seemed surprised and

\footnotetext{
78 Letter, J. Lizars to T. Laycock, n.d. [1 October 1855] \{t\}.

${ }^{79}$ Photograph of J. R. Sibbald $\{\mathrm{p}\}$.

80 Photograph of G. Crichton $\{p\}$.

${ }^{81}$ Photograph of W. Tullis $\{\mathrm{p}\}$.

82 Letter, W. S. Carmichael to T. Laycock, n.d. [1-2 October 1855] $\{t\}$.

${ }^{83}$ List of 1 st and 2 nd votes, calculated on evening of 1 October $1855\{t, p\}$.
} 


\section{Thomas Laycock}

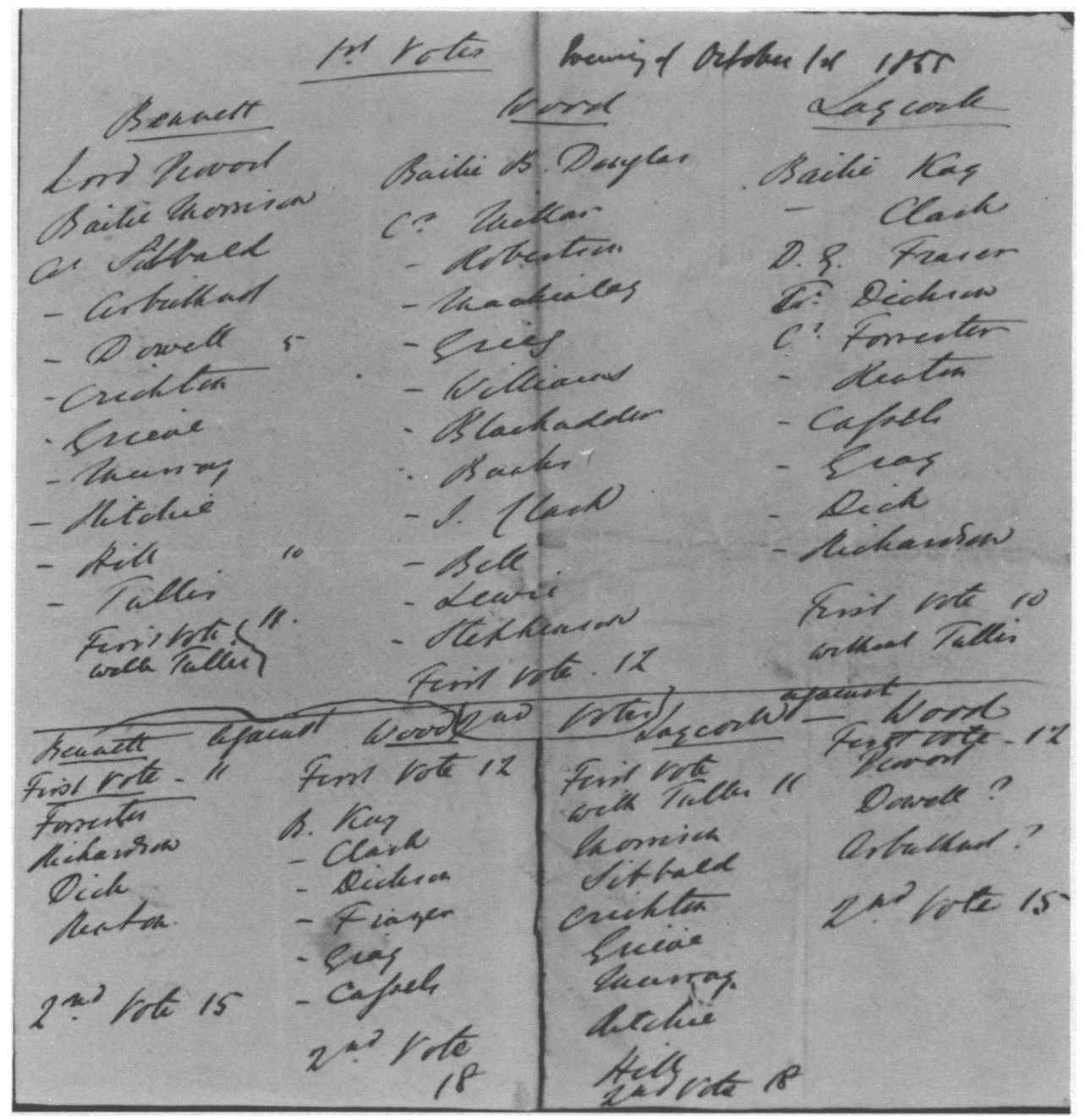

Figure 10: Voting intentions calculated on the evening of 1 October 1855. 
Main Text

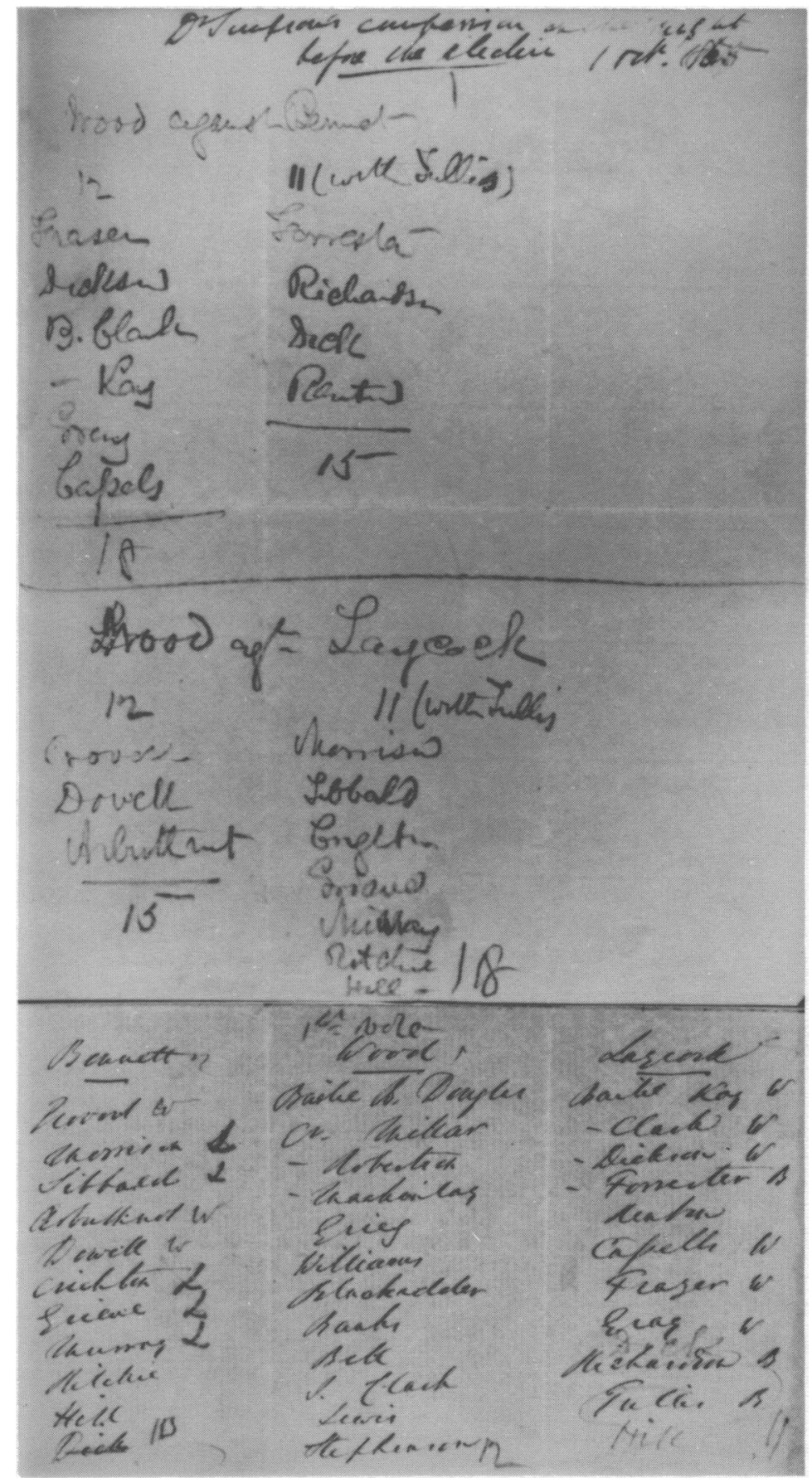

Figure 11: J. Y. Simpson's comparison of votes on the night before the election. 


\section{Thomas Laycock}

indignant at what he considered Mr Gray's defection, and denied at first the accuracy of Dr Laycock's statement. On being assured of it by his own calculations ${ }^{84}$ he rushed out of the house to seek Robert Grieve and another of Dr Bennett's friends and represent with them the helplessness of his chances, the more especially as Bailie Brown Douglas had announced his intention of coming in from the country to support Dr Wood. Dr Laycock retired to rest, wearied with the day's work, but with the strong conviction that Dr Bennett's friends would arrange to secure his (Dr Laycock's) election, failing thus to secure Dr Bennett's. The double failure would, they must feel, render Dr Wood's election the more triumphant, as carried in the face of an absolute majority against him.

On the morning of the day of the election, Dr Laycock awoke to the realities of his position and felt that the responsibilities which would attach to him as occupant of the chair were overwhelming. The stimulus of combat and hope was already lost in the certainty of victory. At an early hour Dr Bennett's refusal to liberate his supporters from his promises was universally condemned. But was there not one who had made no promise? Yes-Mr Alexander Hill, print-seller had not absolutely committed himself. ${ }^{85}$ Mr Hill like others was strongly in favour of Dr Laycock as compared with Dr Wood, and not altogether enthusiastic in favour of Dr Bennett's claims which were rather those of a conventional and local character than of superiority of merit and fitness. Mr Hill, therefore, declared that he would support Dr Laycock in the first instance, under the altered circumstance; for he had only tendered Dr Bennett his support with the hope and expectation of seeing thereby the best man, but did not dispose of his vote to Dr Bennett in absolute right to be disposed of as Dr Bennett pleased. Dr Laycock saw Mr Hill an hour before the election, did not press him in the slightest degree, but heard from him his arguments and views with prefect satisfaction and approval, as both honourable and reasonable.

Mr Robert Grieve, an upholsterer in George Street, was an active friend of Dr Bennett. ${ }^{86}$ He was in known intimacy with Dr Simpson who attended his family in conjunction with Mr Carmichael, and it was generally understood that Dr Simpson had much influence over him. That, however, had evidently been exercised in favour of Dr Bennett, and it was only on the morning of the election that he sought Mr Grieve in favour of Dr Laycock as against Dr Wood. When, therefore, after every possible effort in favour of Dr Bennett he found his case hopeless, he sought Mr Hill in company with others.

Bailie Morrison S.S.C. was an influential leader of the old Whigs and a man of superior conduct and judgement. ${ }^{87} \mathrm{He}$ was very favourably inclined to Dr Laycock as compared with Dr Wood, and therefore took an active part in the morning of the election for securing Dr Laycock's return.

Such, then, was the state of the Town Council on the morning of 2 October 1855, at eleven o'clock when the election was to take place. Dr Bennett was in the agony of disappointment all the more painful because it was the wreck of the hopes and calculations of years. Dr Alexander Wood was so triumphantly certain of his election that he had ordered a champagne lunch to be prepared for his committee and friends to celebrate his

84 List of voting intentions calculated by J. Y. Simpson, 1 October 1855 \{t, p\}.

85 Photograph of A. Hill $\{p\}$.

${ }^{86}$ Photograph of R. Grieve $\{p\}$.

87 Photograph of A. Morrison \{p\}. 
success. Dr Laycock after wandering here and there retired to the back room of $\mathrm{Mr}$ Watson's shop in Princes Street where in solitude (Mr Watson having gone to the Council meeting) he awaited the result in the confident assurance of his election, and where he at last fell fast asleep. From this he was only awakened by Mr Watson walking into the room exclaiming "Professor Laycock! Professor Laycock!"

The order of business was as follows. First the withdrawn candidates were announced; then those who had applied but had no supporters in the Council. One of these was Dr Munro a lineal descendant of the Munros who had been connected with the University of Edinburgh through three generations. Then each candidate was proposed and seconded. After this the Town Clerk called out the names of the councillors who each as his name was called mentioned the name of the candidate he voted for. Dr Wood had twelve votes and Dr Laycock twelve votes; Dr Bennett nine; he was therefore thrown out. This was an unexpected turn to the supporters of Dr Wood. The result of the second voting was awaited with breathless suspense and when $\mathrm{Mr}$ Grieve in an excitable manner and in stentorian voice called out the name of Wood [Laycock], as the clerk named him, a cheer burst forth from both the spectators and the council.

Professor Laycock telegraphed at once to his wife, Sir J. Forbes, Dr Noble, and Dr Henry Johnson of Shrewsbury. ${ }^{88} \mathrm{He}$ then received the congratulations of his friends and especially of Dr Simpson, who gave him an accolade a la Francois [sic]. He also took Dr Laycock about with him in his carriage and made no secret of his satisfaction at $\mathrm{Dr}$ Laycock's success, nor was he shy in receiving intimations that Dr Laycock's success was owing to him. Dr Laycock sent out the annexed circular to all his principal supporters. ${ }^{89}$

\section{(vii) After Victory}

Congratulations follow immediately after victory; then the calm before new struggles. ${ }^{90-99}$ The shrewd remark of the Editor of the Edinburgh News [n 97] that if Dr Laycock had hitherto moved beyond the beaten track of professional routine he could not have failed to have detractors was true enough, as he well knew from much trial and suffering. Nor had his detractors been wholly silent during the canvass, but had alleged against him that he was quarrelsome and litigious. ${ }^{100}$ Victory however silenced them wholly; ${ }^{101}$ so that Mr Samuel W. North, Surgeon, who had sedulously endeavoured with one or two of other young practitioners in York to exclude Dr Laycock from the York

\footnotetext{
${ }^{88}$ Electric Telegraph Company message, T. Laycock to A. Laycock, 2 October 1855 \{t, p\}.

89 Letter, T. Laycock [to Supporters], 2 October 1855 [victory circular] $\{t\}$.

90 Letter, T. Laycock to A. Laycock, 3 October 1855 (t).

91 Letter, A. Laycock to T. Laycock, 2 October $1855\{\mathrm{t}\}$.

92 Press cutting, Daily Scotsman, 3 October $1855\{\mathrm{t}\}$.

93 Press cutting, Edinburgh Evening Post \& Scottish Record, 3 October $1855\{\mathrm{t}\}$.

94 Press cutting, Dublin Medical Press, 10 October $1855\{\mathrm{t}\}$.

95 Press cutting, Medical Times \& Gazette, 6 October $1855\{\mathrm{t}\}$.

96 Press cutting, Yorkshire Gazette, 6 October $1855\{t\}$.

97 Press cutting, Edinburgh News, 6 October $1855\{\mathrm{t}\}$.

98 Press cutting, unidentified Yorkshire newspaper, n.d. [c. 2nd week of October 1855].

99 Unidentified Yorkshire newspaper, n.d. [c. 2nd week of October 1855] \{t\}.

100 Letter, W. Hamilton to T. Laycock, 6 November $1855\{t\}$.

101 Letter, G. Combe to T. Laycock, 3 October $1855\{t\}$.
} 


\section{Thomas Laycock}

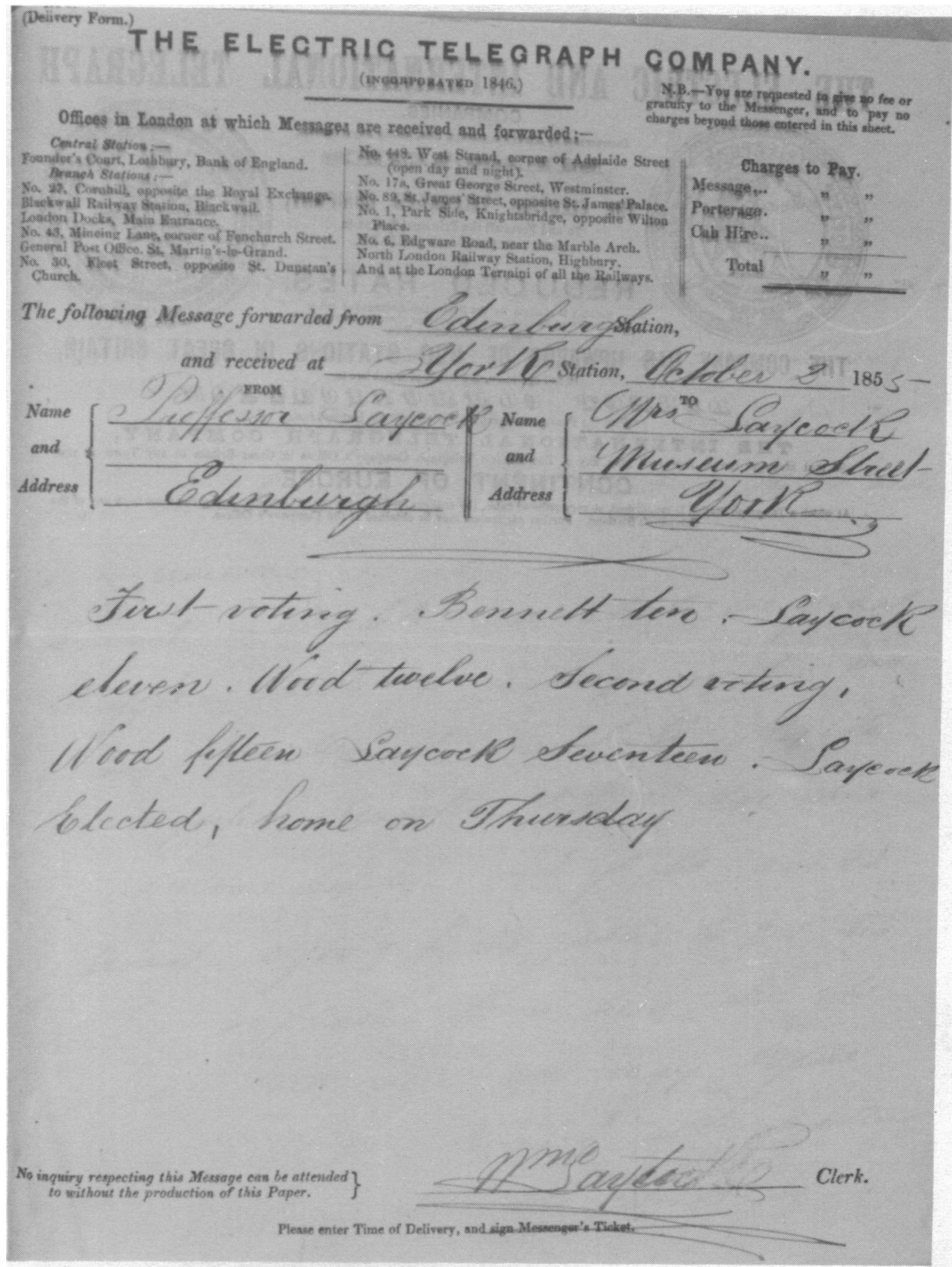

Figure 12: Telegram from Professor Laycock to Mrs Laycock, 2 October 1855. 


\section{Main Text}

Medical Society took the occasion of the opening session at the York Medical School to sing Dr Laycock's praises in the most fulsome terms. The citizens of York felt much as the York Editor expresses himself in the leader from the York Herald? or Yorkshireman? which heads this chapter [ $\mathrm{n} 99$ ]. After allowing Dr Laycock to bear the brunt of the battle with Messrs Hudson and others, almost unsupported, they discovered by a curious psychological process that Dr Laycock's election reflected honour on York. It was at least gratifying to Dr Laycock that the hypocrites washed his tomb before he died, and that success - the test of merit with the multitude-had for the moment at least, extinguished the expression of other feelings, and curbed the detractors. These, however, only bided their time, knowing that the popular applause would soon spend itself and the victor be exposed to the assaults of the vanquished and the envious. One short month had to elapse and the newly elected professor must appear before a crowded and highly critical audience to deliver his "introductory lecture". Within that time he had to make all the arrangements for removal from York to Edinburgh, and not only prepare his lectures but write an article for the Edinburgh Review, which he had promised and which appeared in April following. An attempt was made by some of his friends to give him a public dinner, and a deputation including Mr W. C. Anderson waited upon him for that purpose. The latter gentleman, however, put the proposition in such an extremely offensive manner that Dr Laycock declined the honour. A similar movement was made for a welcoming dinner in Edinburgh, but friends had already cooled down, and the scheme fell to the ground. After much difficulty Mr Robert Chambers secured a furnished home in York Place, at the rent of $£ 220$ for six months, and on 1 November Dr Laycock left York with his family arriving early in the morning at Edinburgh, after a stormy wet journey, the water flooding the rails. Mrs Chambers had kindly provided fires for the travellers, and the real business of the professorship commenced.

Dr Laycock was not long in discovering that his course would be most arduous. Professor Simpson he ranked as a friend to advise wisely, but it was soon made clear that no reliance could be placed on him. He did not even attend Dr Laycock's introductory lecture, on the ground that his presence was needed at the College of Physicians, where (Dr Simpson alleged) it was the intention to make Dr Laycock submit to an examination before he could be admitted a fellow, on the ground that he was a foreign graduate. But this was wholly absurd because the professor of the Practice of Medicine in the University could claim to be an honourary Fellow ex officio as provided by the Royal Charter.

On 5 November Dr Laycock gave his introductory lecture in the chemistry class-room which was filled to overflowing. He had not had time to do more than jot down the heads of his lecture so that it was delivered ex tempore. A correspondent however of the Medical Times and Gazette (said to be Dr A. Wood) pretended to deduce from the absence of [a] manuscript that Dr Laycock had got his lecture by rote. His class was an unusually numerous one, numbering above 140 , some of whom were returned medical officers of the army, while that of Dr W. T. Gairdner, who had intimated his expectation to do more than compete successfully, was a complete failure. But this was in accordance with the popular notion that the successful are always in the right. It was not long, however, before Dr Laycock found a bitter spirit of hostility was felt by some of his colleagues, and from that time forth, these did everything in their power to destroy Dr Laycock's popularity and turn students to the classes of his Extra-Academical rivals. 


\section{Thomas Laycock}

Professor John Lee, Principal of the University, in referring to the departure of Professor Alison from the Senatus when he delivered his discourse to the students at the opening of the session (as was his custom) while he praised the outgoing, had no word of welcome for the incoming Professor of the Practice of Medicine. On the contrary, he expressed his wish that the doubtful anticipations as to the latter might not be verified, in such a manner as to imply that he feared they would be.

Dr Bennett, in particular, was possessed by what appeared to be an insane spirit of rivalry and opposition, which in the course of the next summer and autumn hardened into a settled plan of antagonism as clinical teacher at the Infirmary. In the meanwhile he was moody, walked along the street muttering to himself and gesticulating as if addressing an imaginary audience and gave other signs of deeply perturbed spirits. Nor was it possible for Dr Laycock to do full justice to his new position. Certain persons thought it right to show him hospitality, others sought his public services at meetings, and thus the time which should have been devoted to his lectures was otherwise occupied. And as he had determined to recast his course, he had to prepare each lecture from day to day, and consequently to labour into the night to the injury of his health and mental powers. In the meanwhile, envy was busy with its slanders and exaggerations and false friends were lending their aid to the envious by damning him with false praise.

Dr Simpson, upon whom Dr Laycock had every reason to rely as a support in practice, failed wholly to call him into consultation in any case after Christmas 1855. At Dr Simpson's death on 6 May 1870 the entire fees received by Dr Laycock from cases in consultation with Dr Simpson could not be estimated at more than fifty guineas. The latter had recommended Dr Laycock to two patients he was not able to visit, viz. one at Cupar in 1858 and Mr J. P. Orde of Kilmany in 1867. And having recommended his old man servant Tom Clarke to Dr Laycock as butler and janitor, he used him as a spy upon all Dr Laycock's family and other proceedings. So that he even informed of so trivial a fact that Dr Laycock and his wife went to early communion on Christmas Day!

The year did not end happily. While at York during the Christmas recess Dr Laycock learnt that his second [child], George Lockwood, had a severe convulsive attack. Dr Simpson attended him, and ordered leeches. Those bled very profusely so as to weaken the child much. The directed effects of this attack continued until George Lockwood went to school at Trinity College, Glenalmond in September 1866. And the following spring was not encouraging in various ways, but the misgivings thus excited were nothing as compared with the force of the violent attack which was impending and being prepared for. In May 1856 Dr Laycock took his turn of clinical duty at the Infirmary and removed to number 4 Rutland Street.

\section{(viii) "Envy, Hatred Malice, and All Uncharitableness"}

The Session of 1855-56 passed over without any overt act of hostility, but certain notices of motion given as early as January 1856 by Dr Bennett, indicated that a resolution had already been taken by him to offer the most uncompromising opposition to $\mathrm{Dr}$ Laycock both in teaching and practice, and circumstances facilitated Dr Bennett's efforts.

Dr Christison preceded Dr Laycock as clinical teacher in the spring of 1856 and left patients in the clinical wards for Dr Laycock to treat when he succeeded on 1 May. Amongst those was a young man whose disease was marked "phthisis" by Dr Christison 